\title{
Understanding Cancer by Whole Genome Studies
}

\author{
Authors: $\quad$ Christof von Kalle \\ Submitted: $\quad$ 5. November 2016 \\ Published: $\quad$ 5. November 2016 \\ Volume: $\quad 3$ \\ Issue: $\quad 6$
}

Keywords: $\quad$ cancer, whole genome studies, bioethics, symposium

DOI: $\quad$ 10.17160/josha.3.6.248

\section{JOSHA Jumualositumea Humanities and Arts}




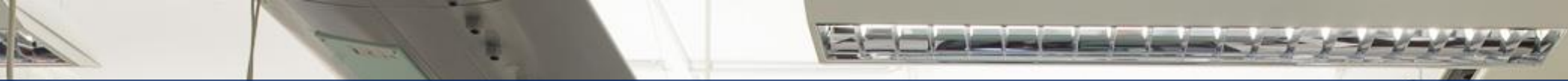

\section{Understanding Cancer by Whole Genome Studies}

Christof von Kalle NCT Heidelberg

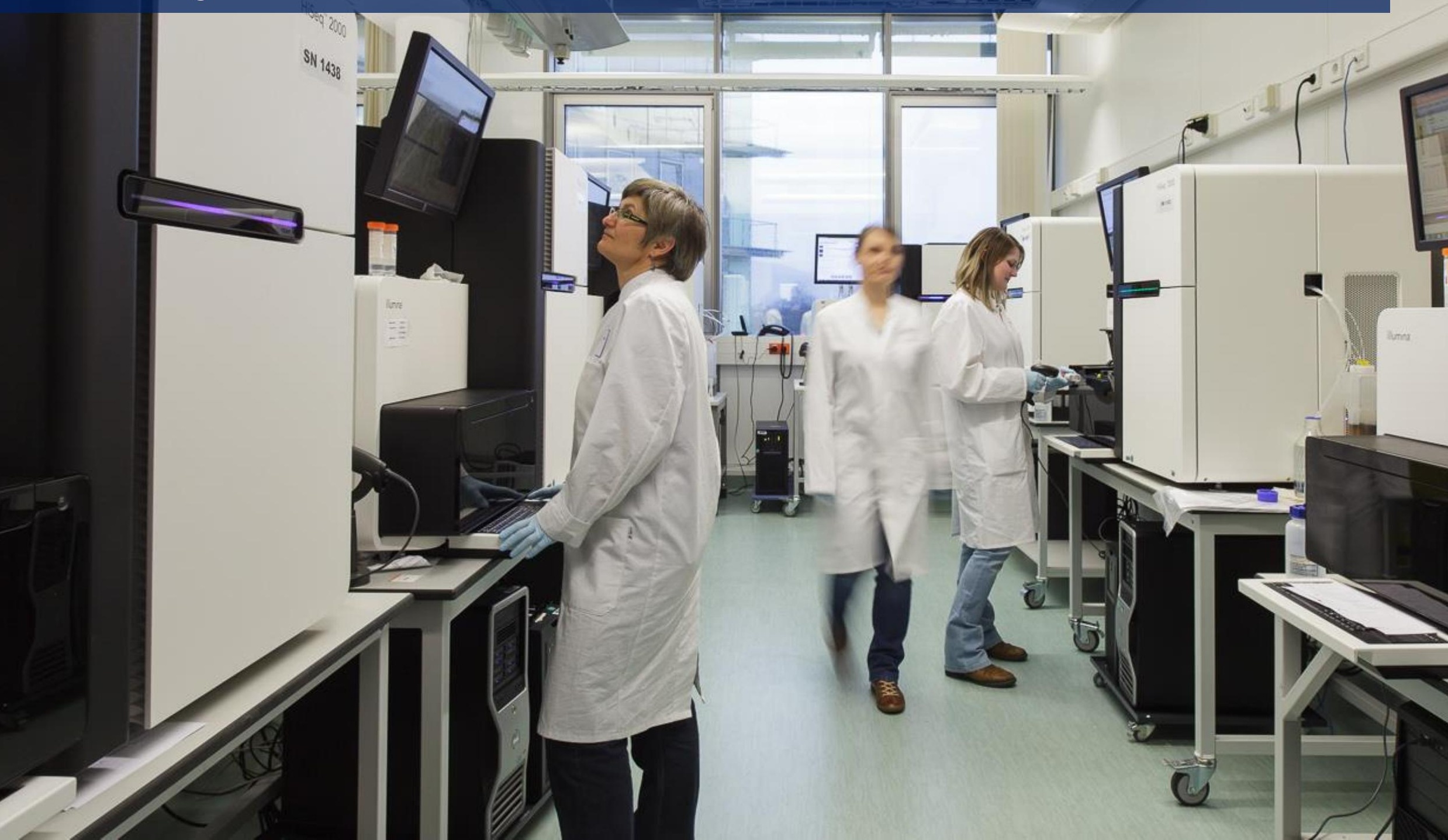


Oncology - A Leading Topic in Heidelberg

\section{EXCELLENCE in}

* Clinical Translation and Basic Research

* Clinical and Translational Cancer Programs

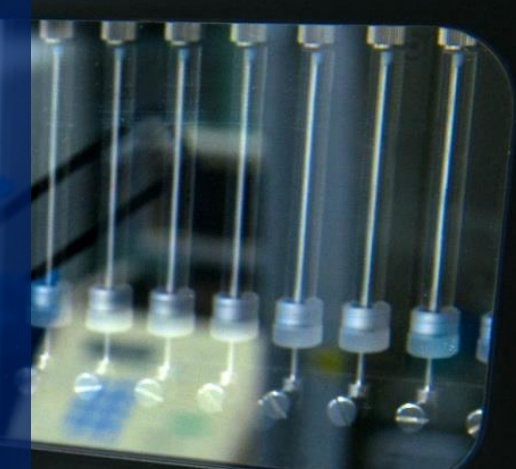

* Interdisciplinary Patient Care 


\section{NCT - Interdisciplinary Patient Care}

Heidelberg University Medical School

61.210 Inpatients, 50.042 Day Hospital Cases

G-DRG Case-Mix 2012: 109.975 Index: 1,797

426.760 Outpatient cases / 1.029.920 Visits (2012)

\section{NCT 2013}

Newly Diagnosed Patients: 9.802

Out-Patient Visits: 55.235

Treatments: 19.300

Patients Enrolled in Clinical Trials: 20,4\%

232 Clinical Trials, >70 HD IITs (2010/2012)

\section{Clinical Care}

Cancer Research Grants 


\section{NCT 1.0 - Principles \& Practice}

\section{ONCT}
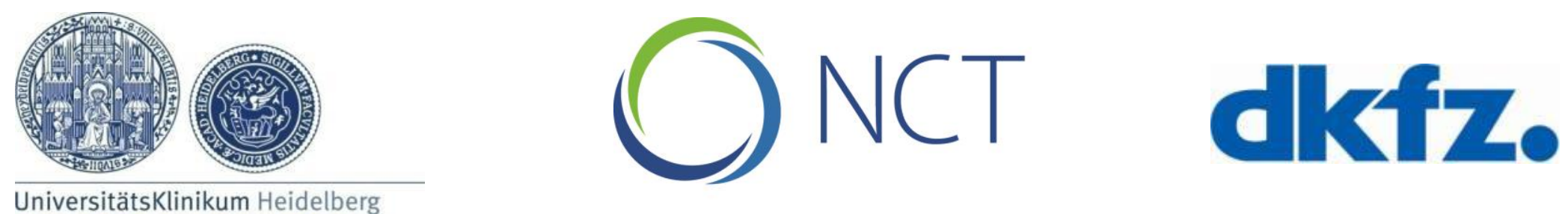

UniversitätsKlinikum Heidelberg
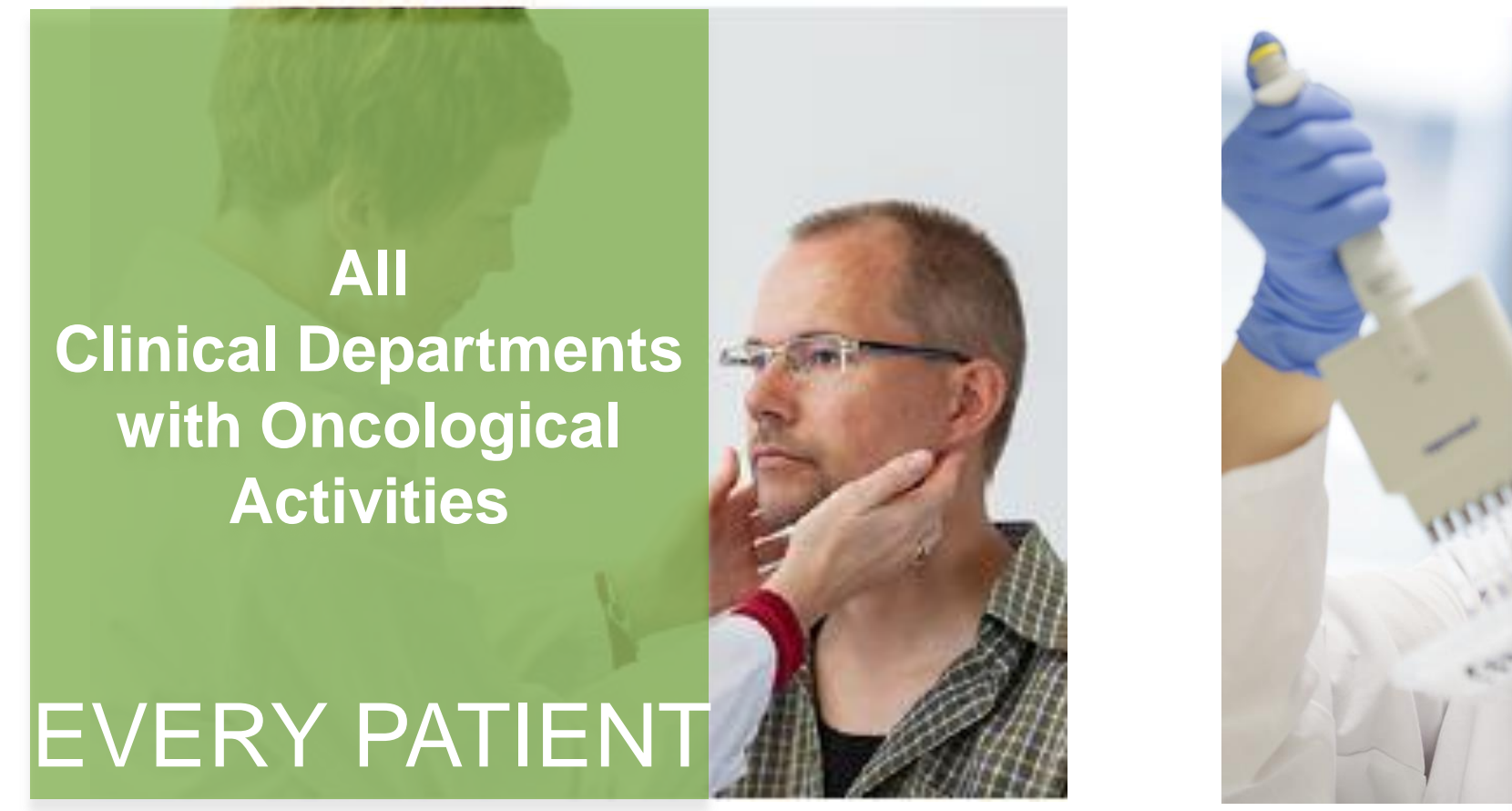

All

Translational Cancer Research Groups

\section{EVERY TRIAL}

\section{Creating Interdisciplinarity}


NCT 2.0 - New Building \& Structures

O NCT
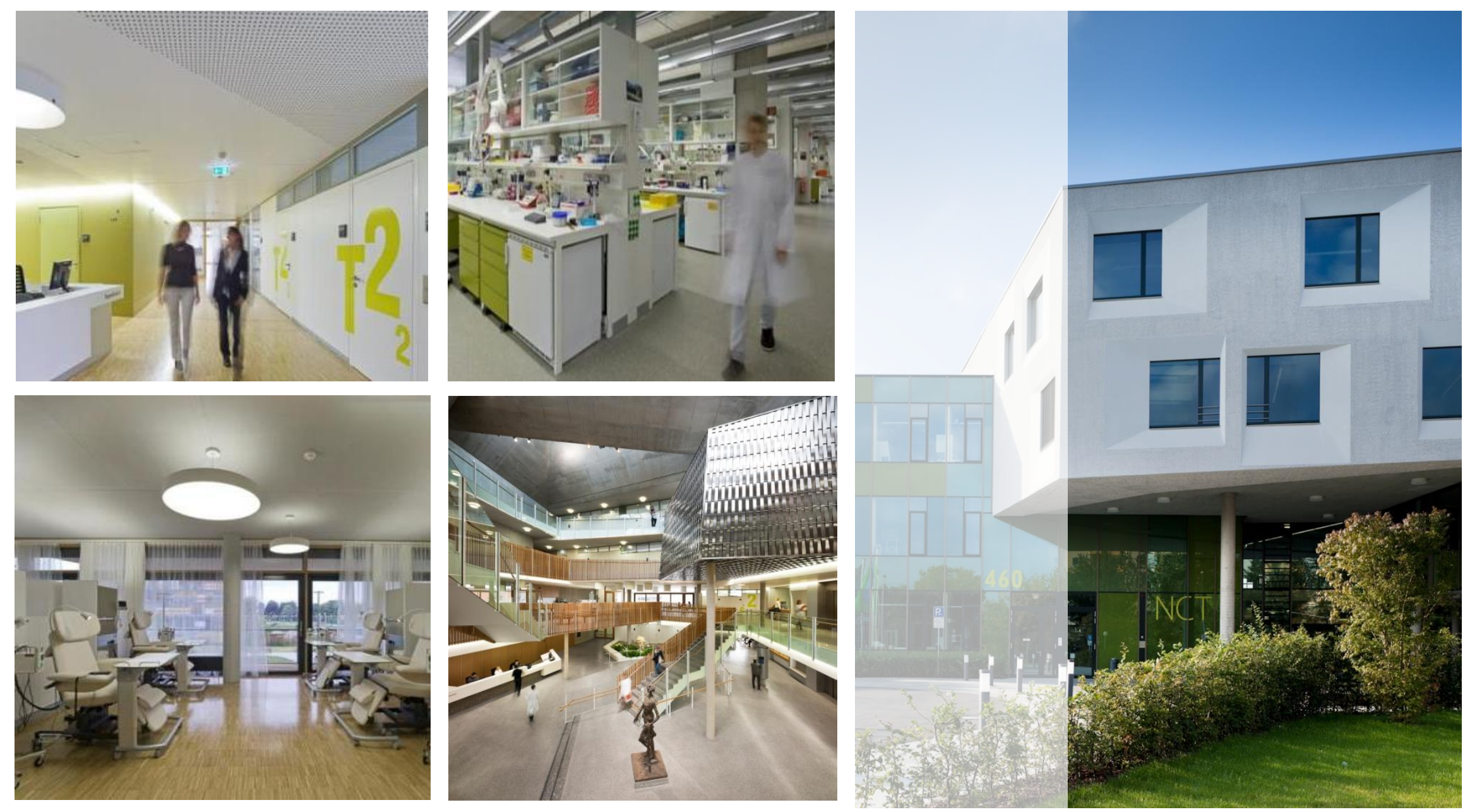

IDENTITY \& VISIBILITY 
NCT 3.0 - The Next Level

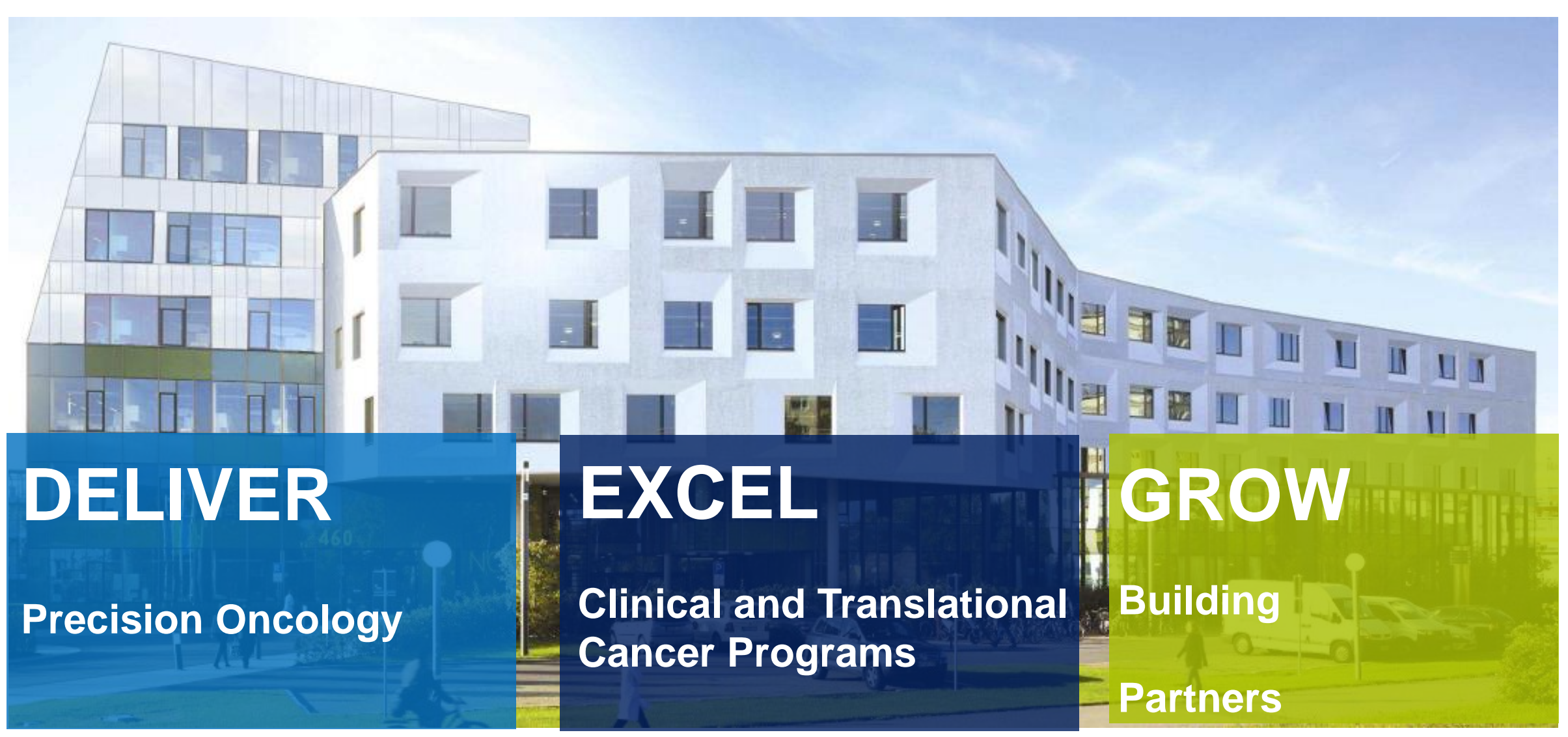

\section{SCIENTIFIC \& CLINICAL EXCELLENCE}




\section{NCT 3.0 - Strategic Aims}

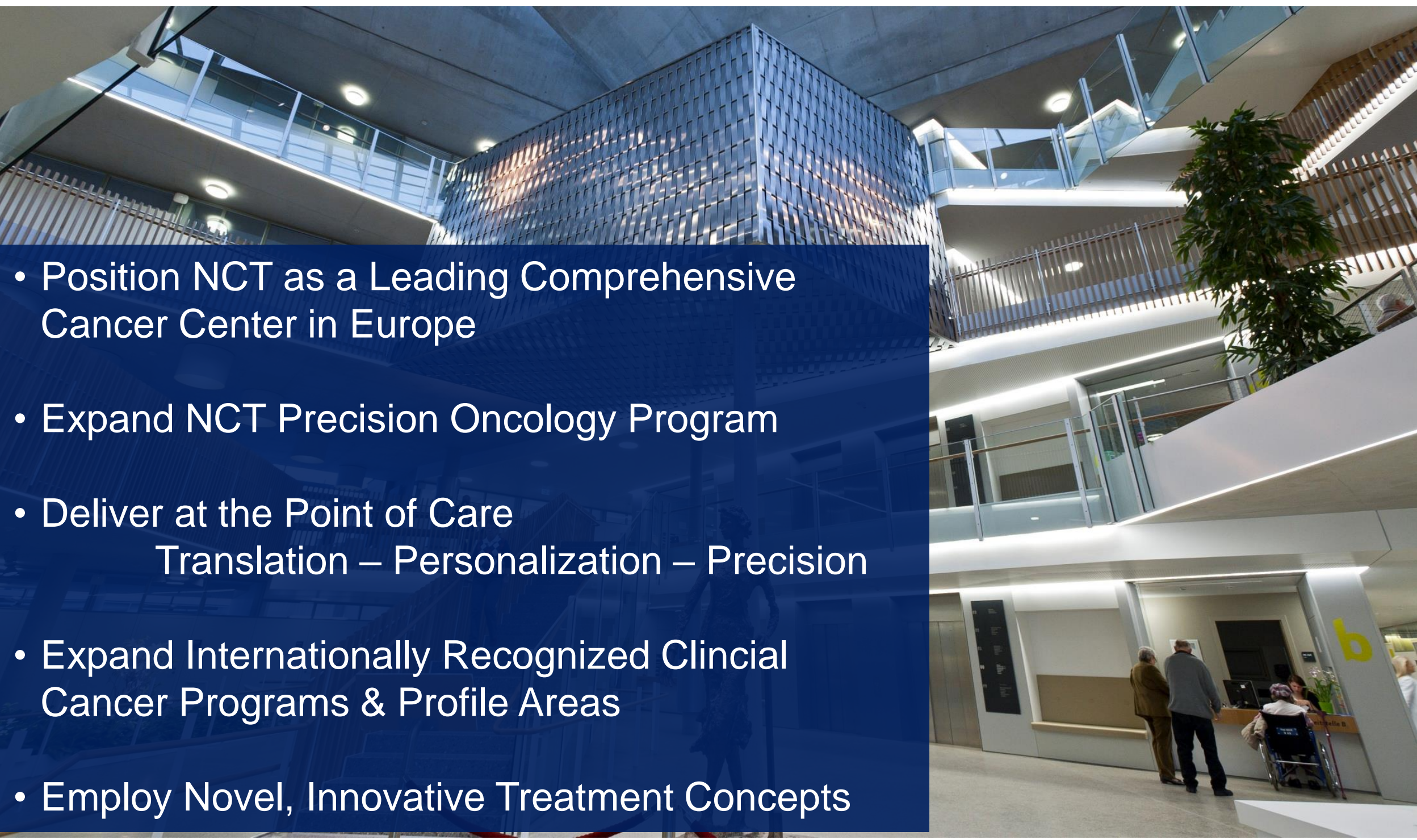

- Position NCT as a Leading Comprehensive Cancer Center in Europe

- Expand NCT Precision Oncology Program

- Deliver at the Point of Care

Translation - Personalization - Precision

Expand Internationally Recognized Clincial Cancer Programs \& Profile Areas

- Employ Novel, Innovative Treatment Concepts 
NCT 3.0 - Programmatic Funding

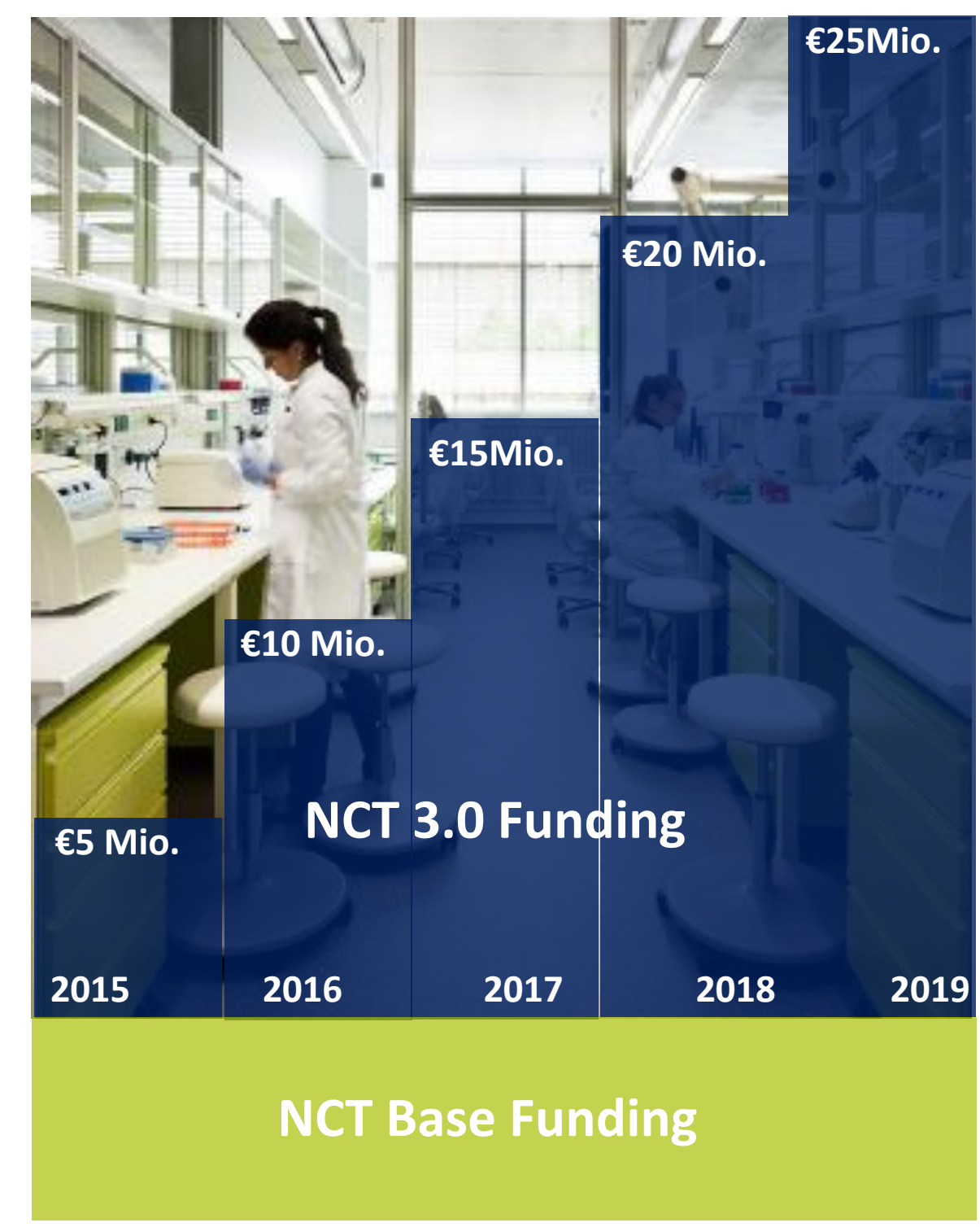

Building Extension

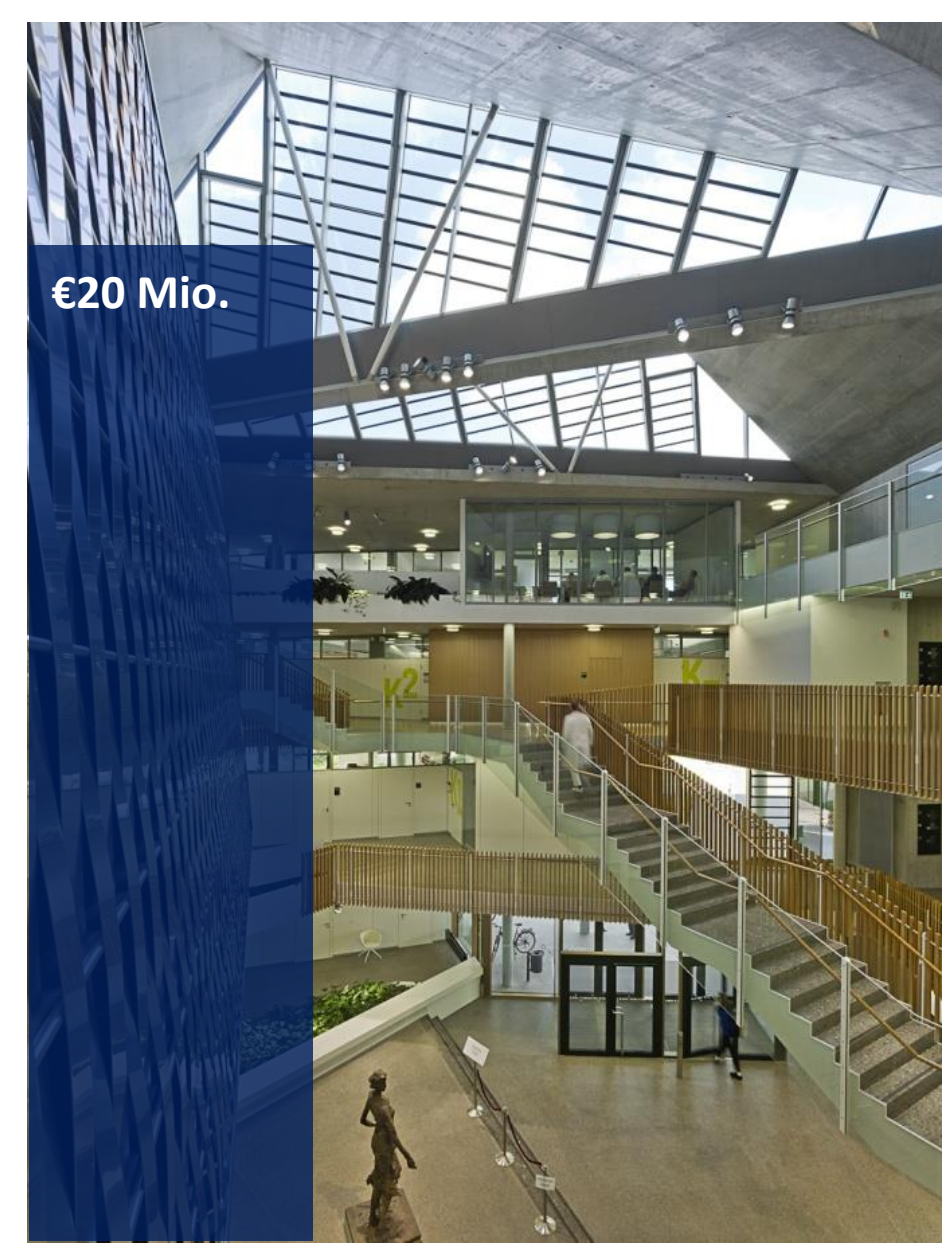


NCT 3.0 - Profile Areas to be Expanded

\section{DELIVER \\ EXCEL}

* NCT Precision Oncology

* Novel, Innovative

Treatment Concepts

* Clinical Trials \& Biobanking Infrastructure/Expertise

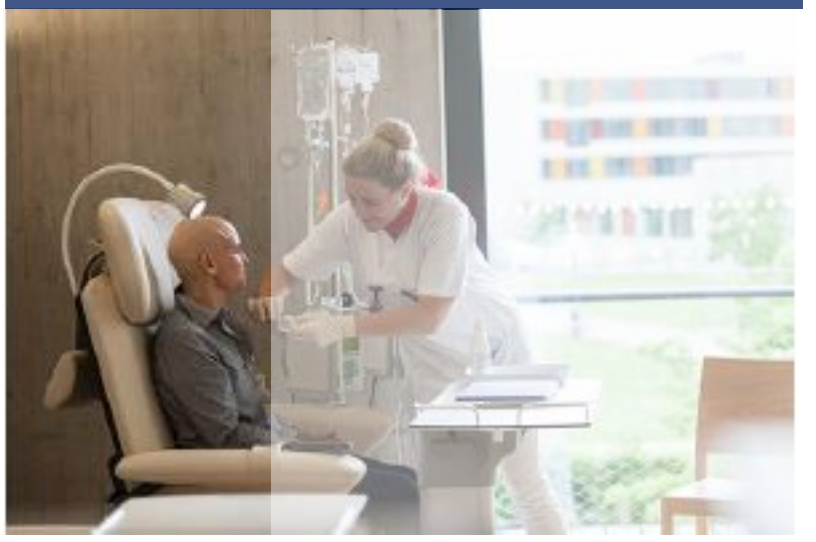

* Molecular Stratification

Immunotherapy

* Profile Areas -

Neurooncology

Pancreatic Cancer,

Radiooncology,

Lung Cancer,

Prostate Cancer

* NCT OncoCheckProgramm

* Innovative Oncological Imaging

* Molecular Tumor Pathology

* Biomarker Platform

* NCT DataThereHouse \& Cancer Registry

* New Programs CardiOncology, Palliative Oncology, Hematology

* NCT Basic Research Pipeline

\section{GROW}

* Partnerships

* Funding Programs

* Recruitments

* Talents

* Facilities
매는

미므.

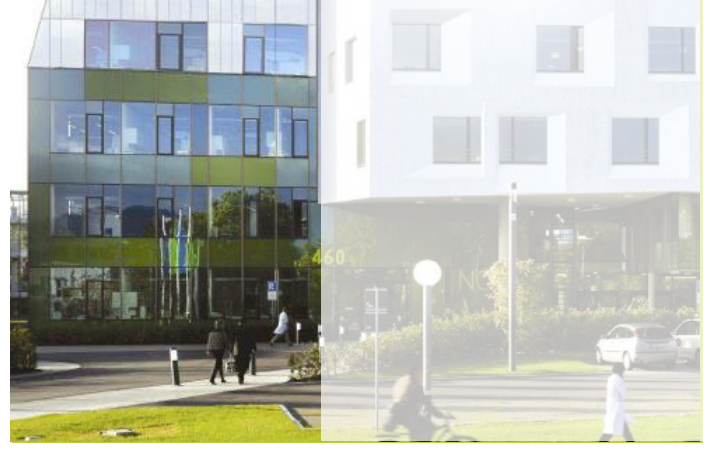


NCT Precision Oncology Program

STRATIFIED ONCOLOGY
CLINICAL EVALUATION \&
TRIALS
DATA
INTEGRATION
TARGET
EXPLOITATION
TARGET
CHARACTERIZATION

\section{EARLY DIAGNOSIS}

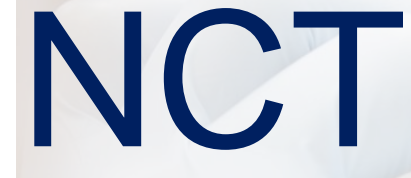

\section{RISK STRATIFICATION}

\section{INDIVIDUALIZED \\ THERAPY} SAP HANA

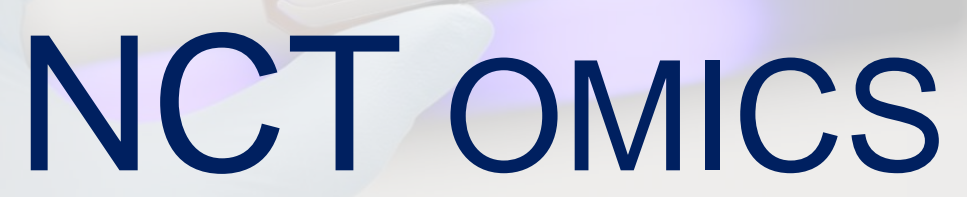




\section{The Paradigm Shift:}

Imaging each Individual Patient's Cancer At the Molecular Level

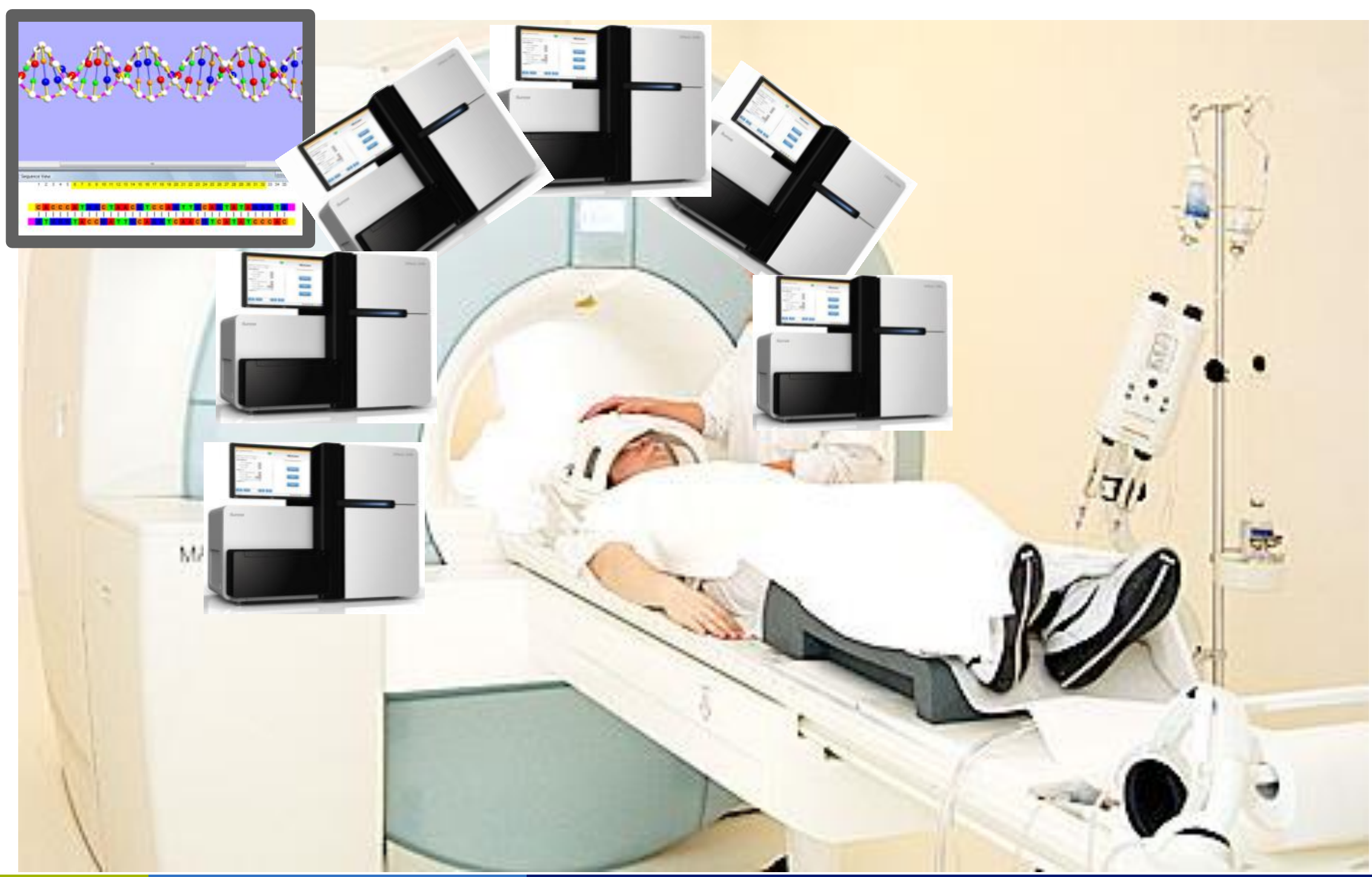




\section{Heidelberg Center for Personalized Oncology}
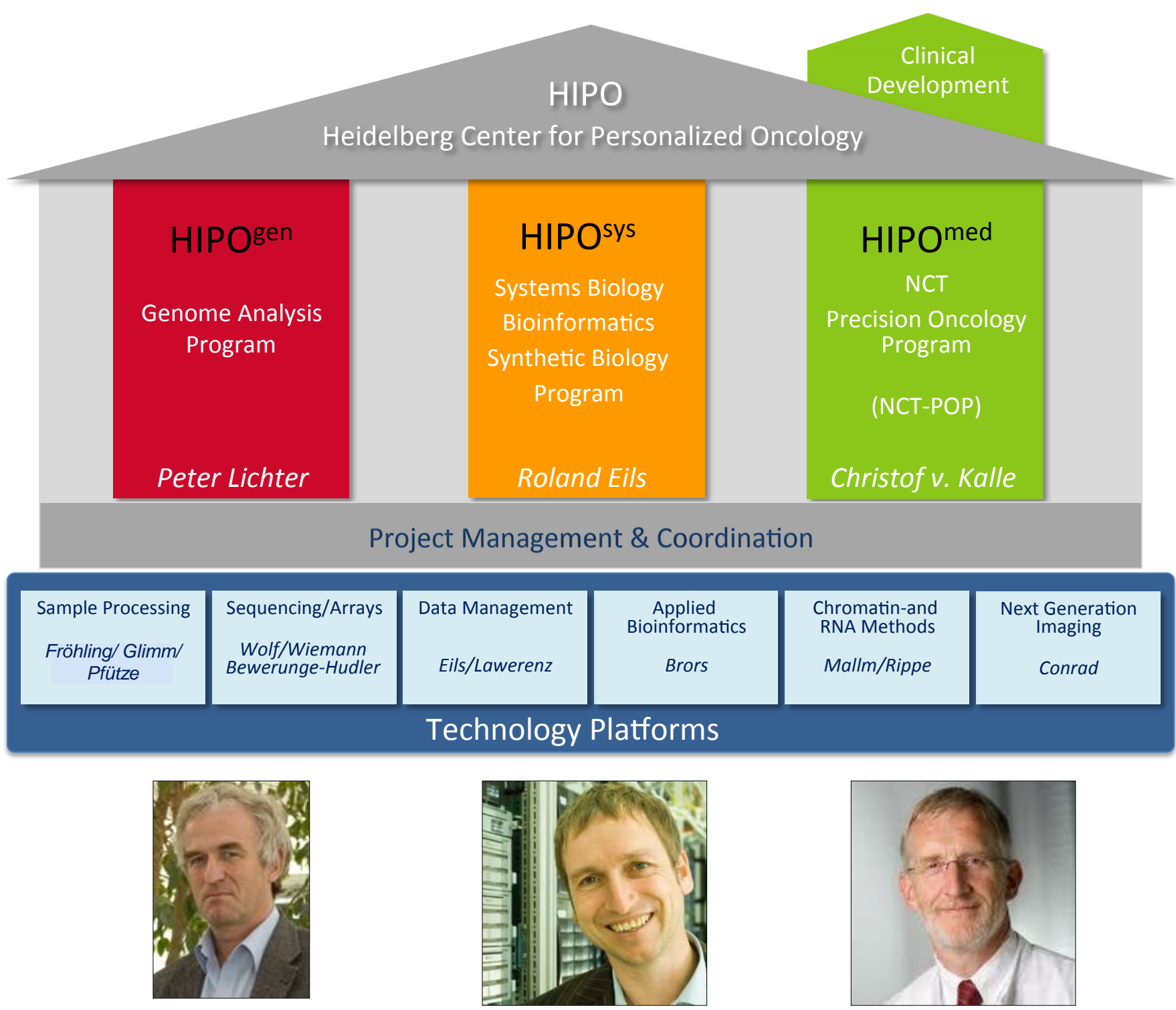


\section{NCT Precision Oncology Program}

\section{Stratified Oncology}

Target Charaterization

Target Identification

Patient Admission Documentation Banking
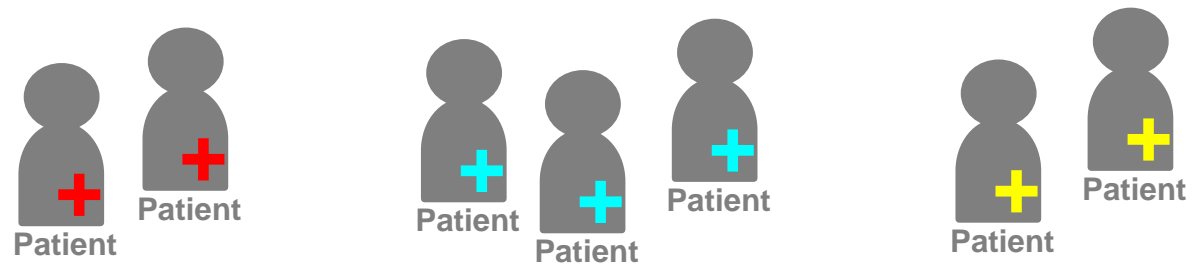

NCT
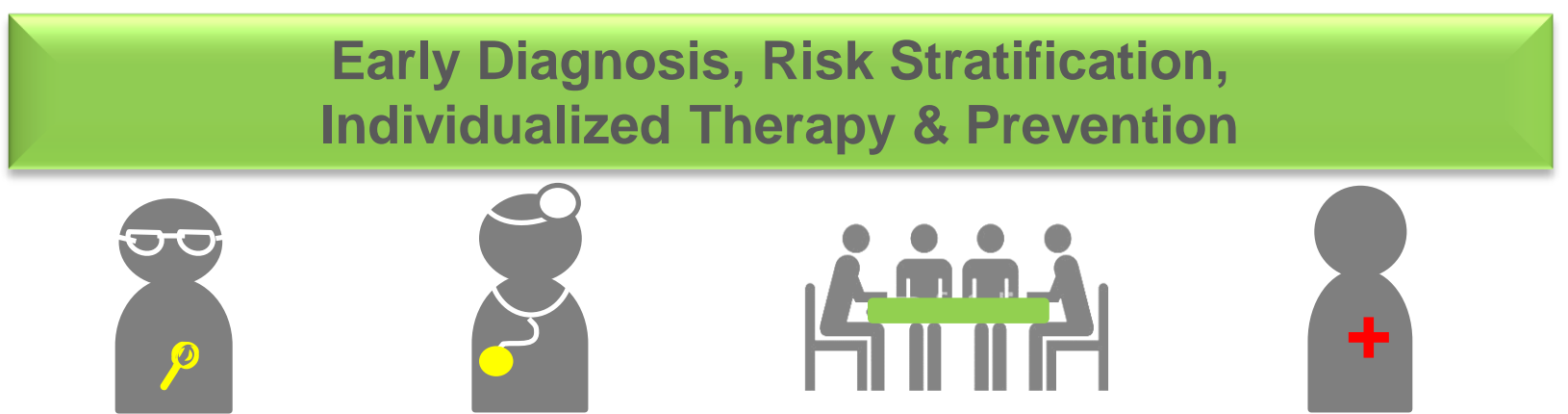

$$
\text { Researcher }
$$

Physician

Molecular Tumor Board

Patient
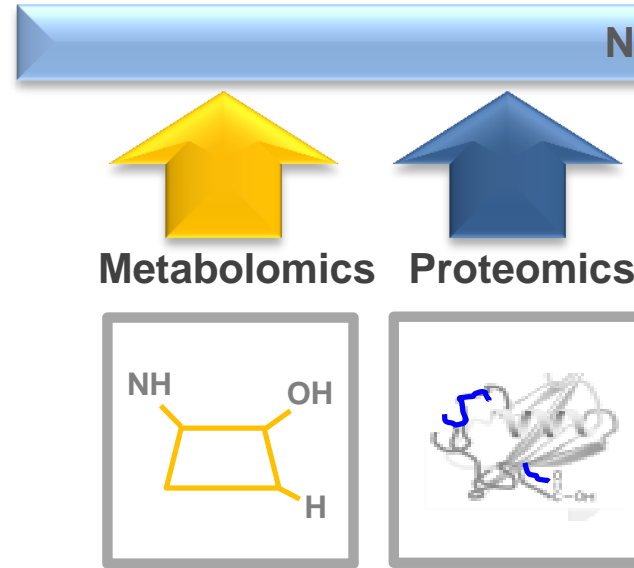

NCT DataThereHouse
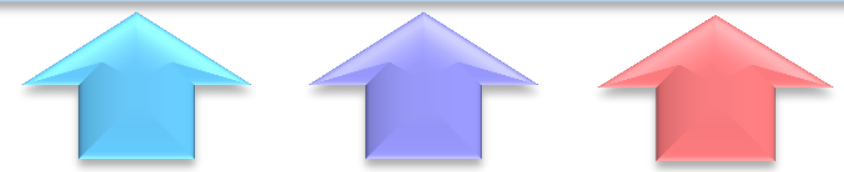

Genomics Immunomics

Radio/Imaging
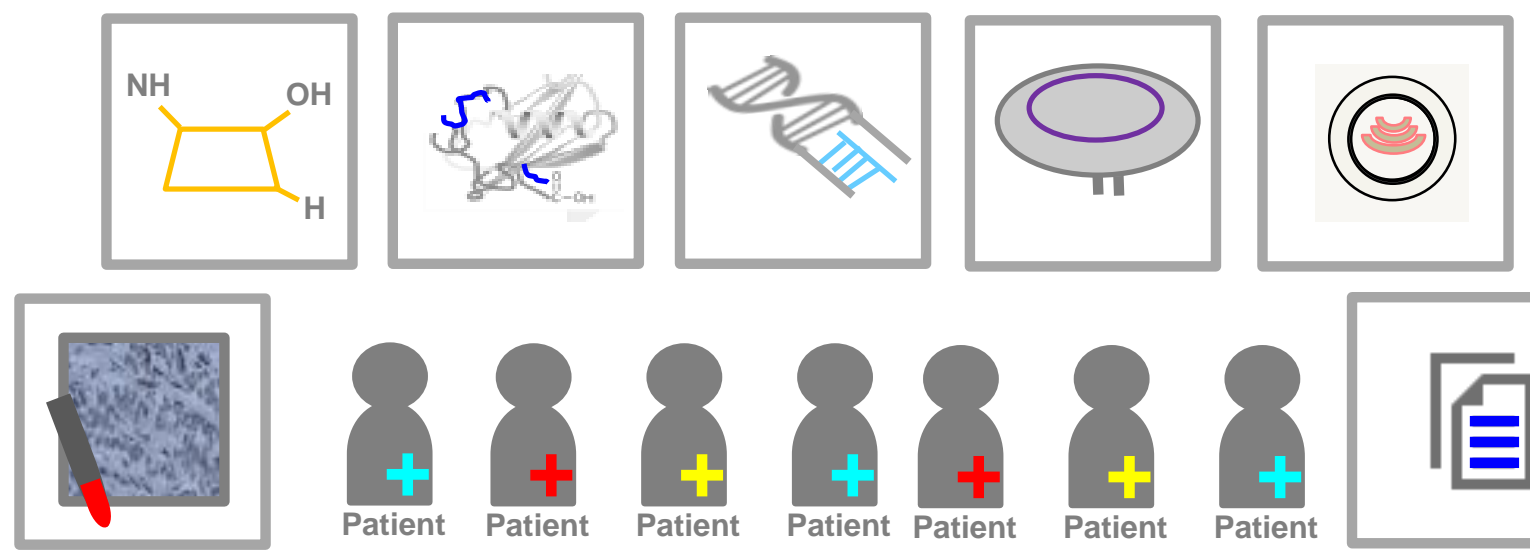

Biomaterials

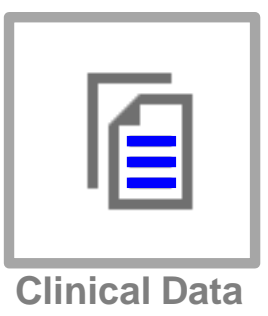



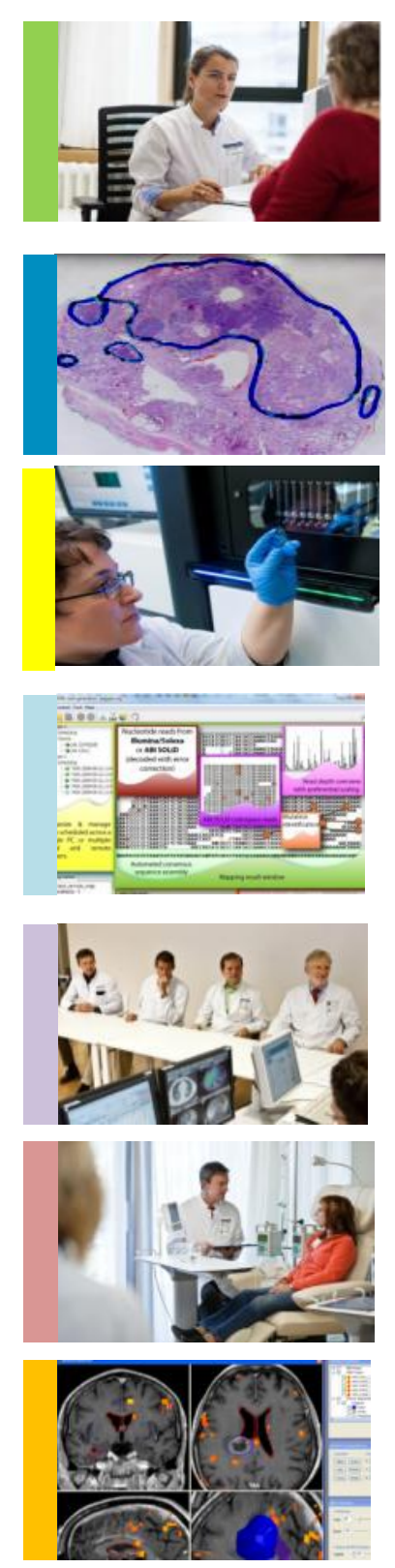

PATIENT ADMISSION ENROLLMENT CLINICAL DATA

DIAGNOSIS \& SAMPLING

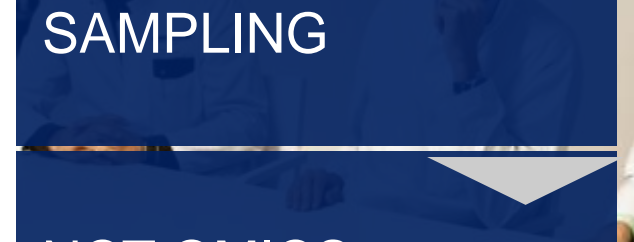

NCT OMICS

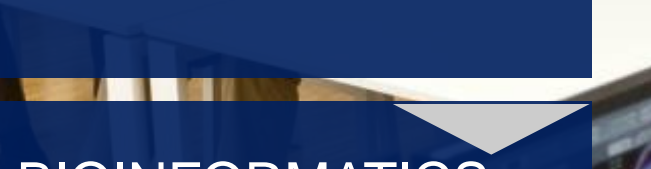

BIOINFORMATICS CLINICAL REPORT

MOLECULAR TUMOR BOARD

INDIVIDUALIZED THERAPY \& TRIALS

RESPONSE RESISTANCE PREVENTION

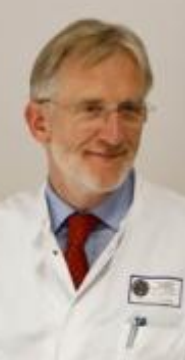

$\Rightarrow$ 패

$>$ an I

$+$

$+$

$+$

$>\square \square$

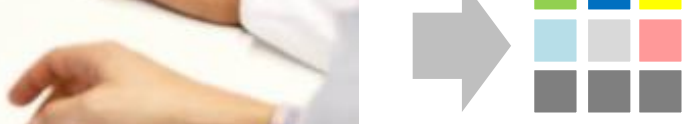

$+$ 


\section{National High Throughput}

\section{Sequencing Core Unit}
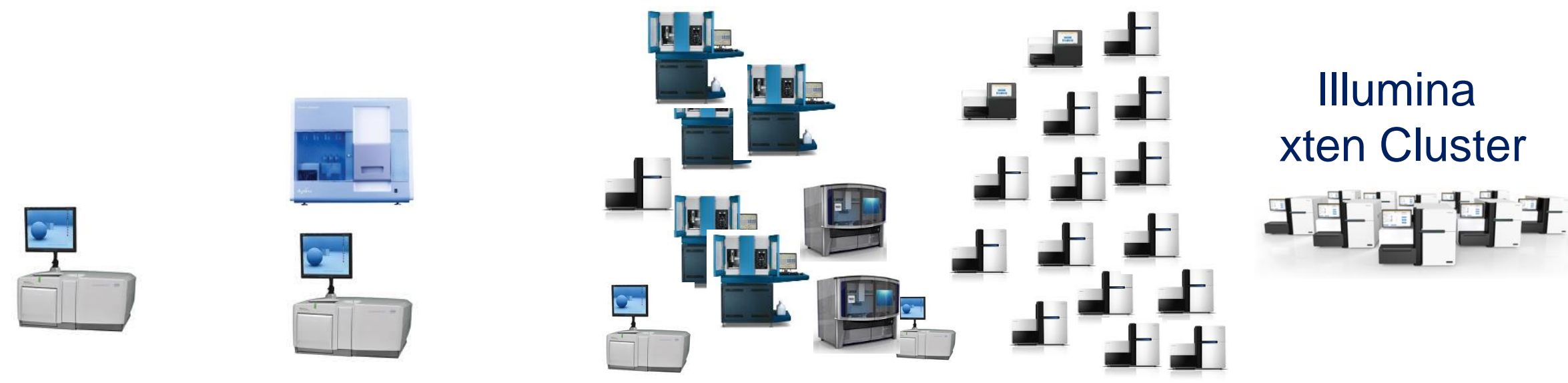

2009

2010

2011

2012

2015

NCT Precision Oncology Program

ICGC

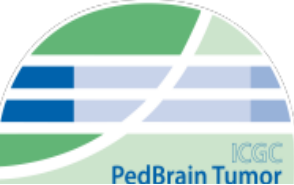

International

Cancer Genome

Consortium dkfz.

INFORM

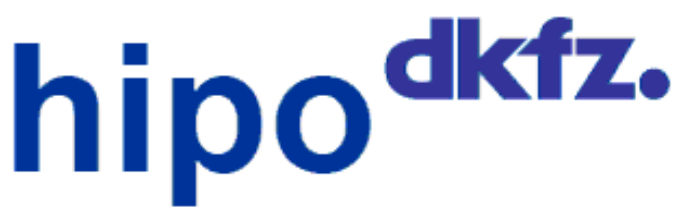

NCTPOP

Deutsches Konsortium
für Translationale
Krebsforschung 


\section{DNA Sequencing Methods Applied in Oncology}

\section{ONCT}

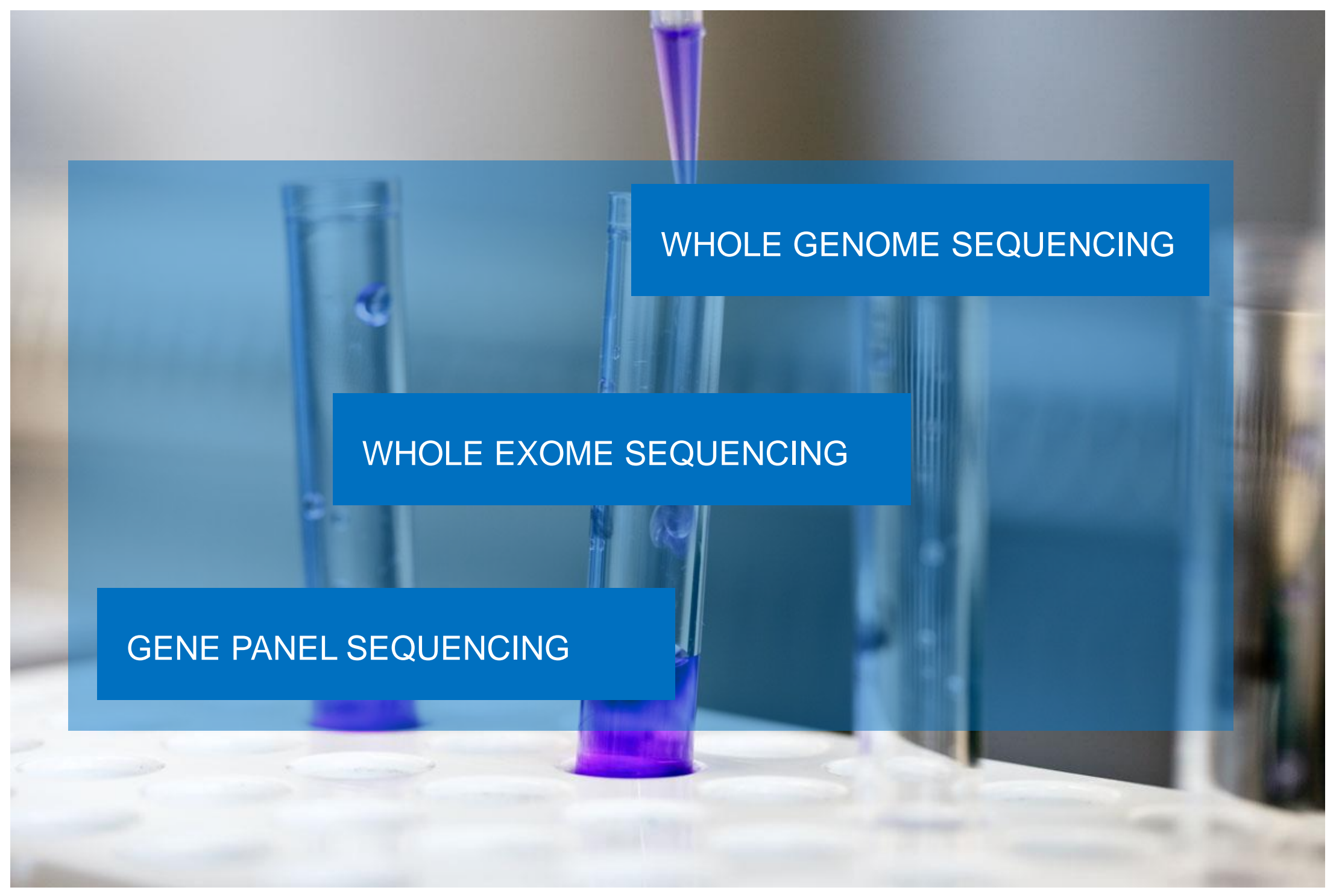




\section{Cancer genome sequencing}

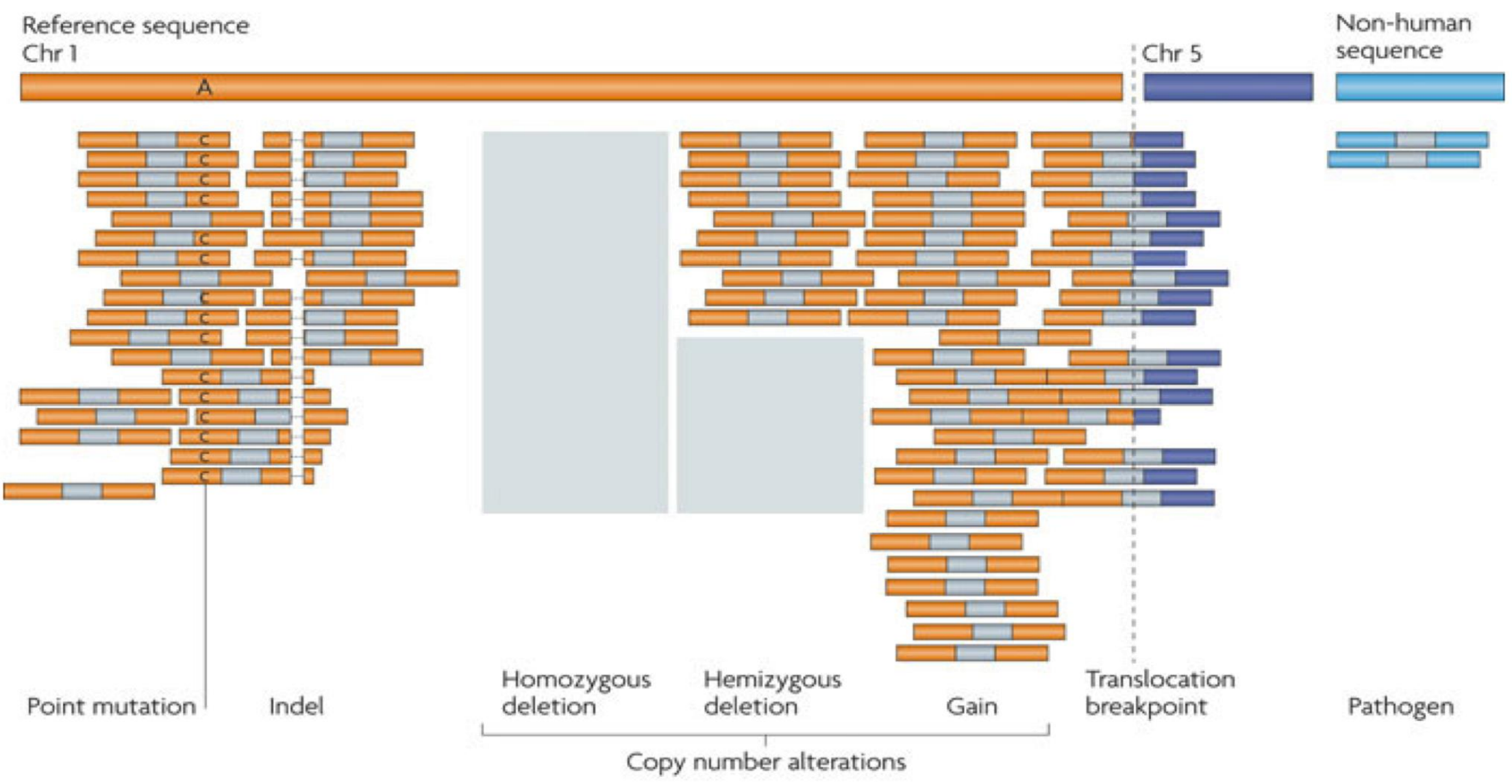

Meyerson, Nat Rev Genet 2010 


\section{Applied Bioinformatics}

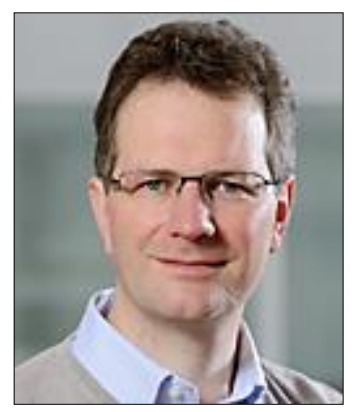

Benedikt Brors

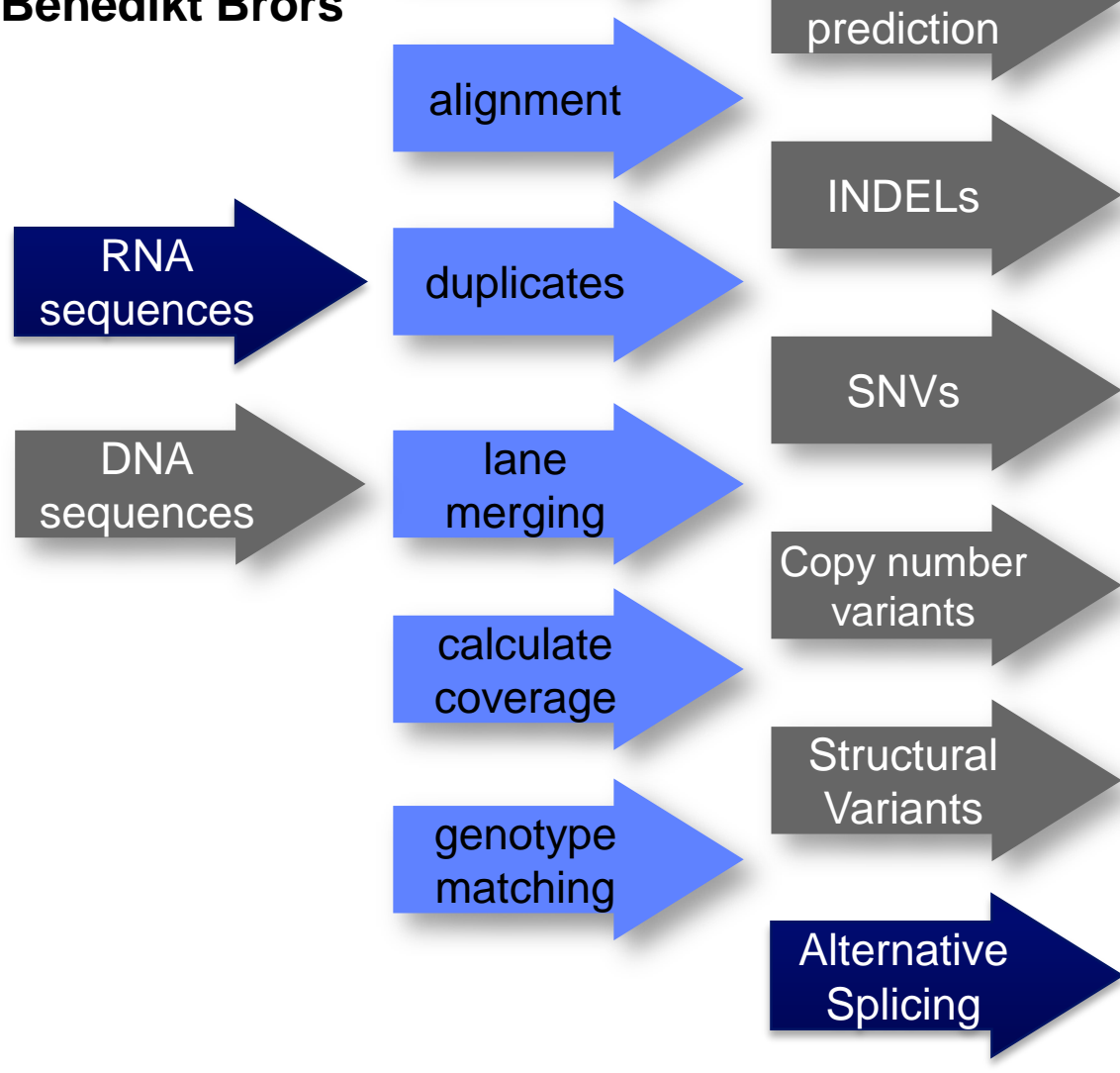

$\begin{array}{cc}\text { PRIMARY } & \text { SECONDARY } \\ \text { ANALYSIS } & \text { ANALYSIS }\end{array}$

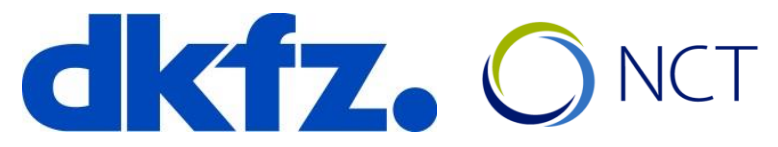

TERTIARY ANALYSIS: „INTERPRETATION"
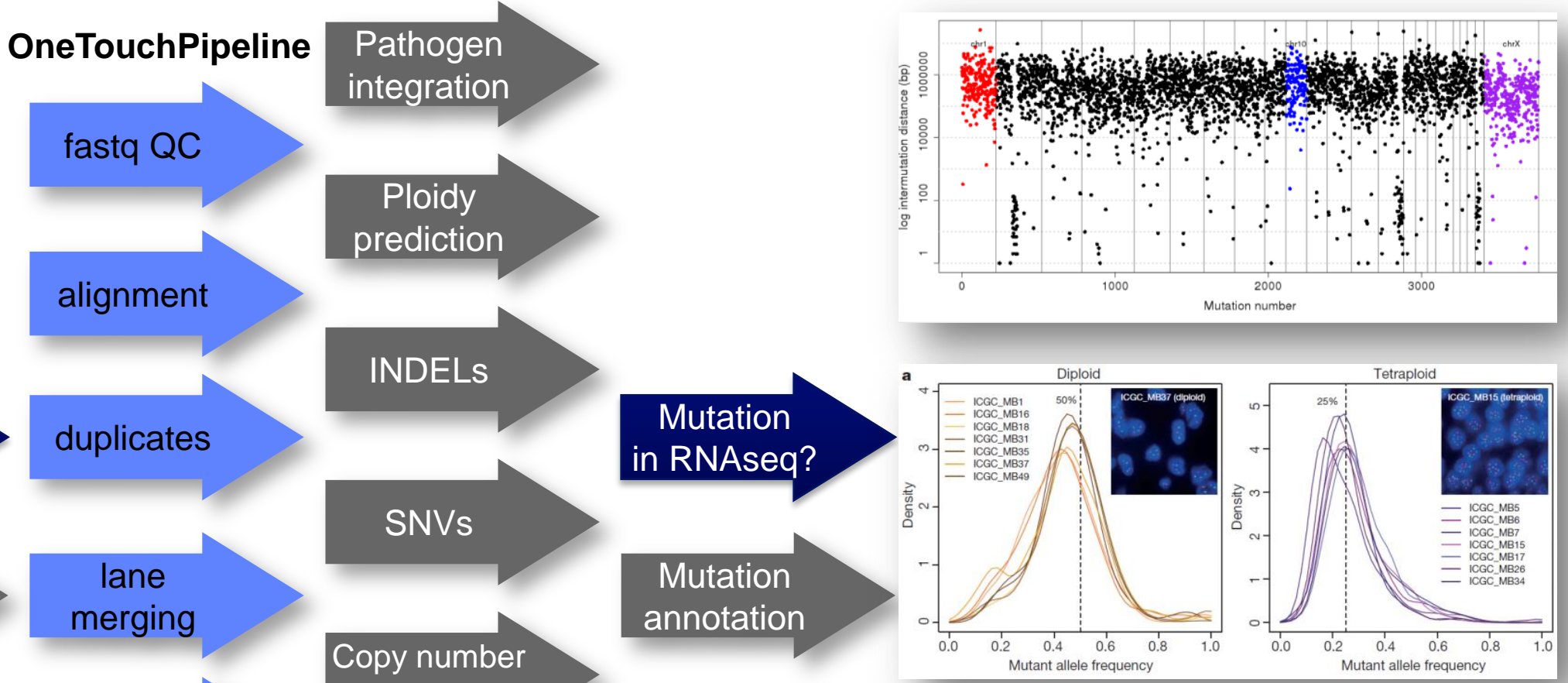

Mutation

annotation

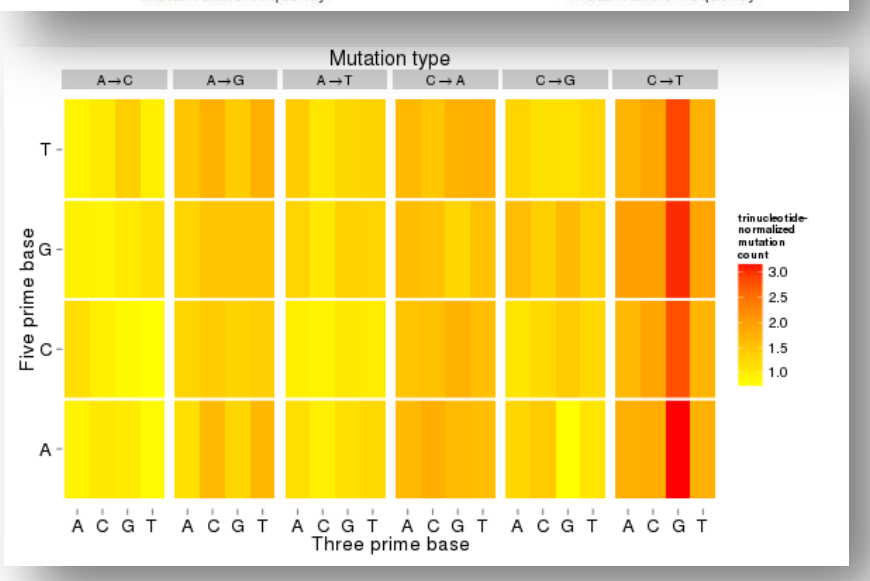




\section{NCT MASTER - Registry \& Interventional Trial}
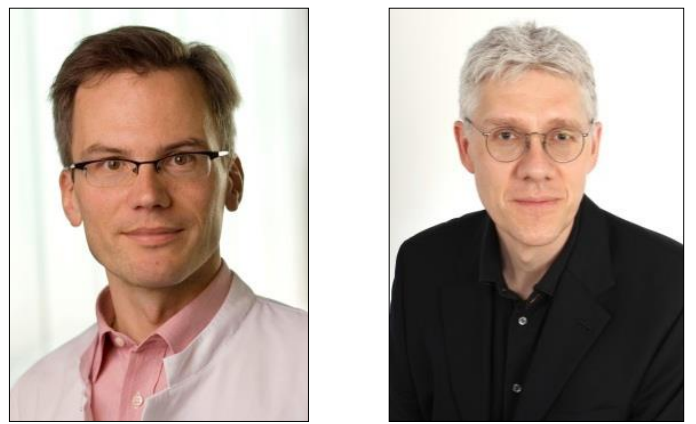

\section{Hanno Glimm Stefan Fröhling}

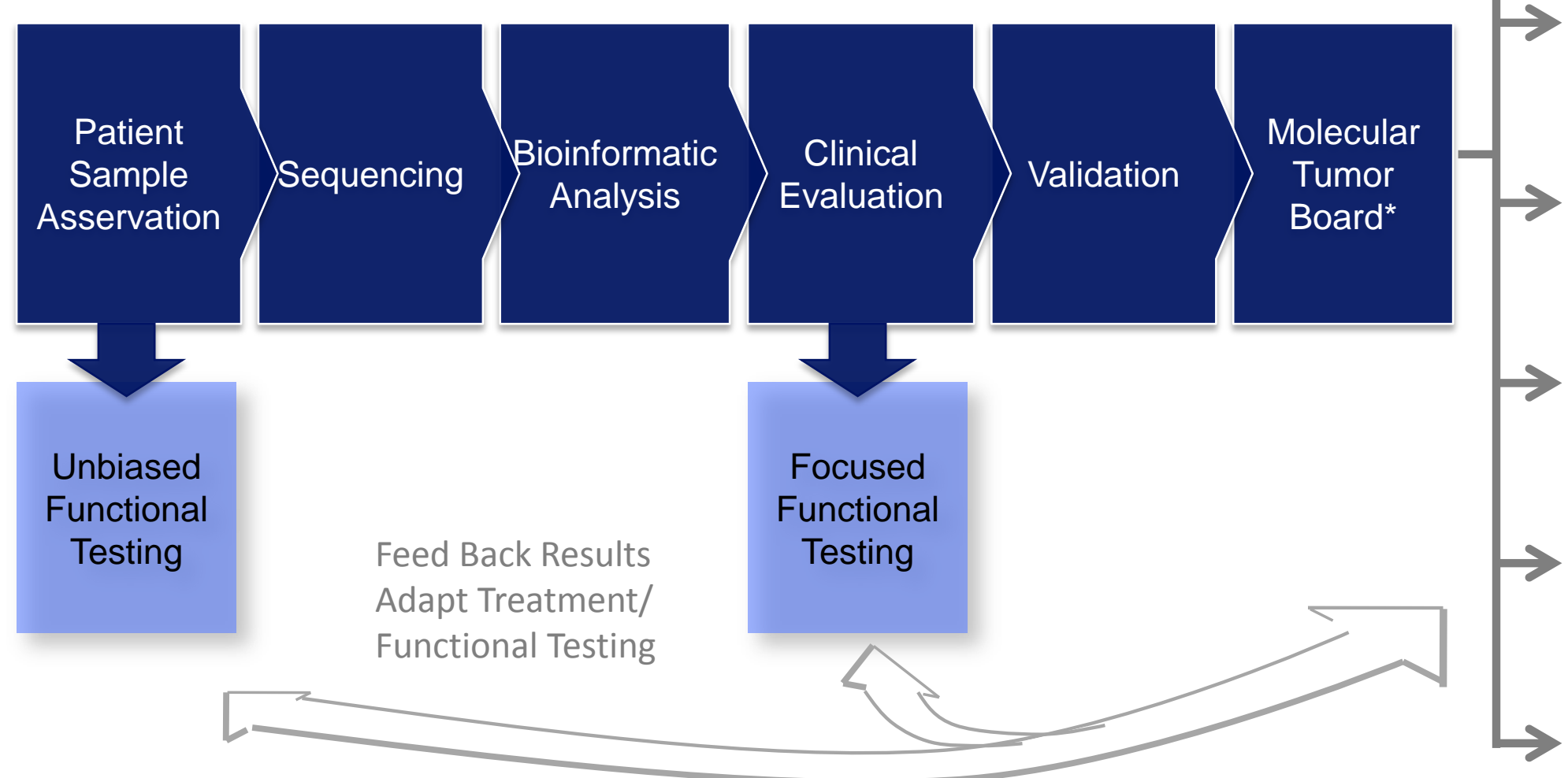

RAF-MEK
ERK

PI3K-AKTmTOR

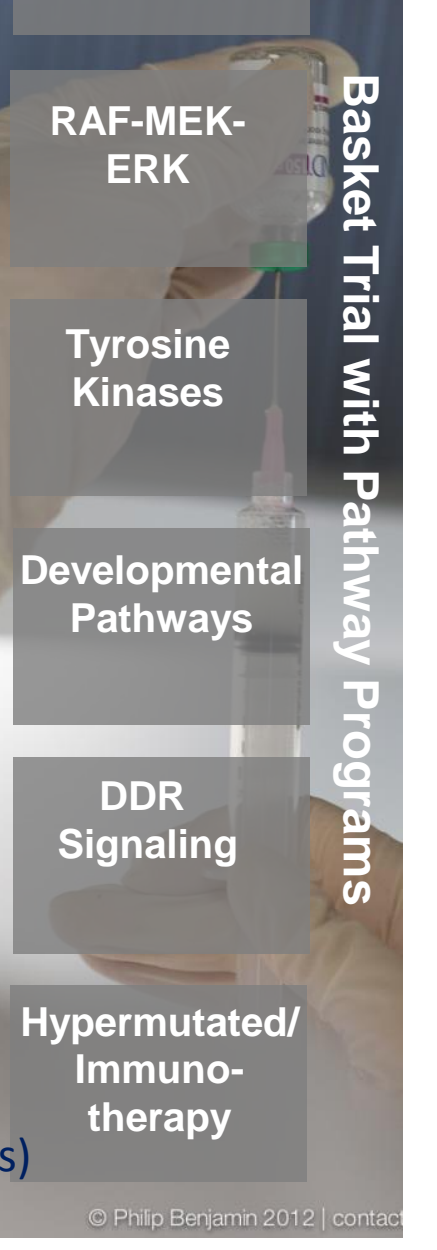

Stefan Fröhling, Christoph Heining, Hanno Glimm, Stefan Gröschel, Claudia Sch
DKTK - LMU München, Frankfurt, Dresden, Essen/Düsseldorf, Freiburg, Berlin 


\section{NCT MASTER - Registry \& Interventional Trial}

\section{CURRENT STATUS}

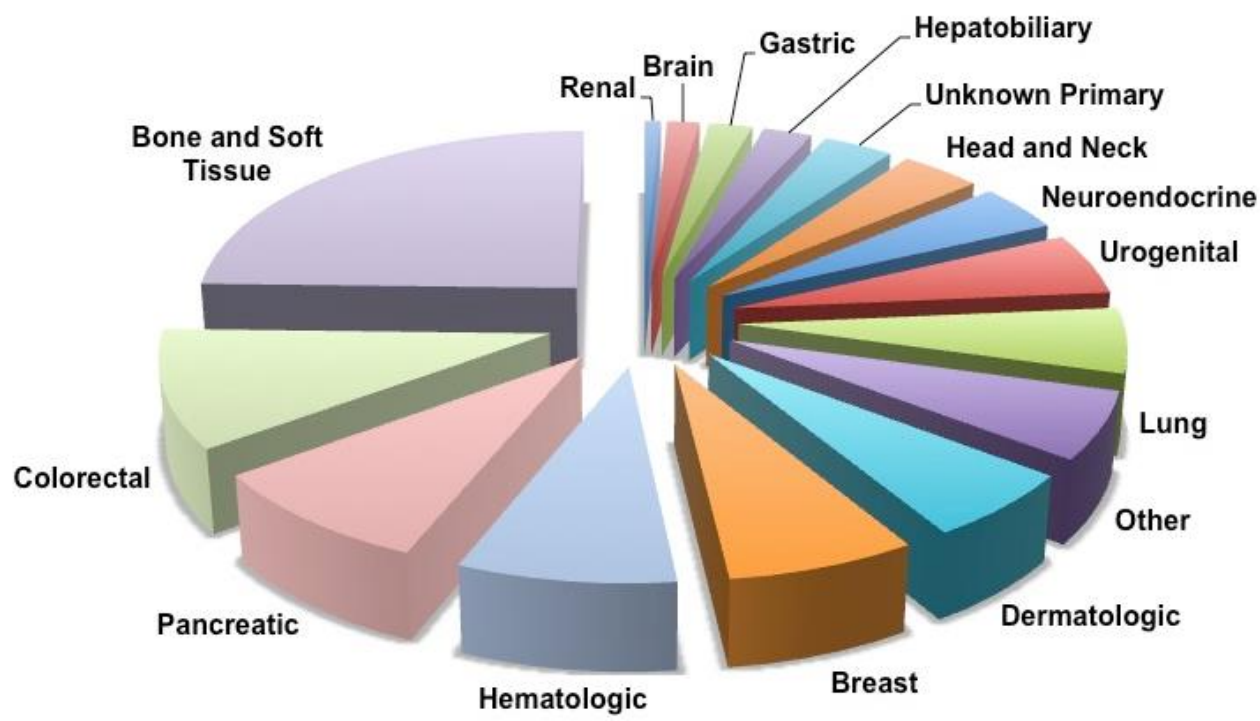

\section{Entities}




\section{NCT MASTER - Case Report I)}

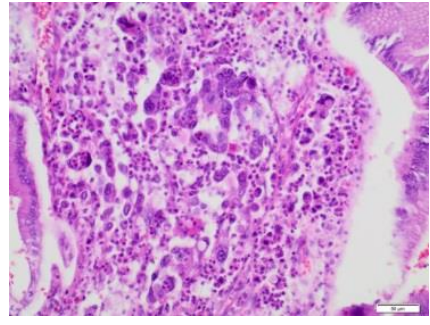

$H \& E$
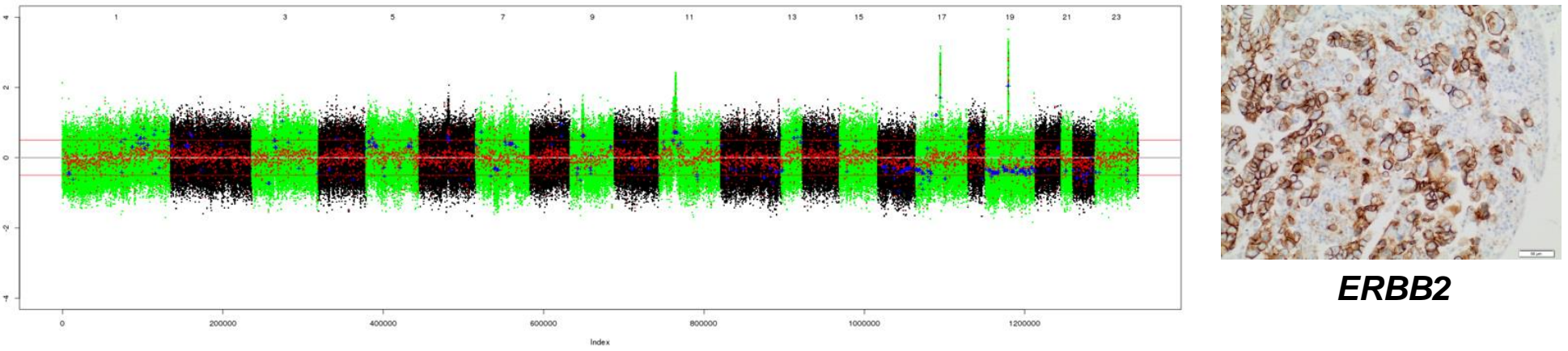

Metastatic gallbladder carcinoma

- Peritoneal and cutaneous metastasis during adjuvant chemotherapy with oxaliplatin/gemcitabine

Amplification of chromosome 17q12, including ERBB2

- Outlier ERBB2 mRNA expression

- $\quad$ ERBB2 protein expression by immunohistochemistry (3+ according to ASCO guidelines)

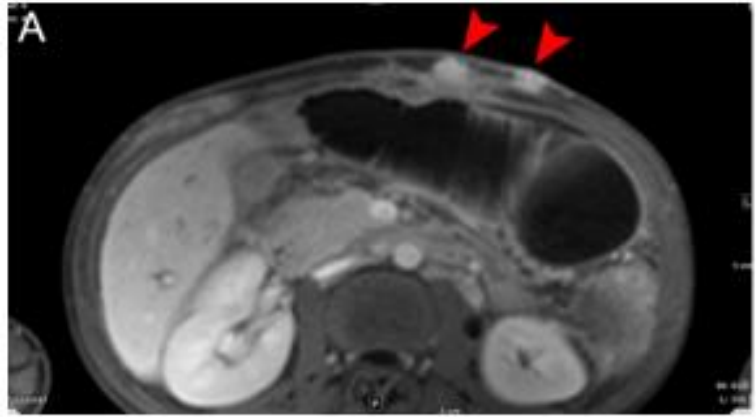

Dual ERBB2 blockade: trastuzumab/pertuzumab

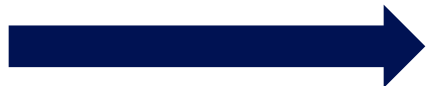

Complete remission for $>12$ months

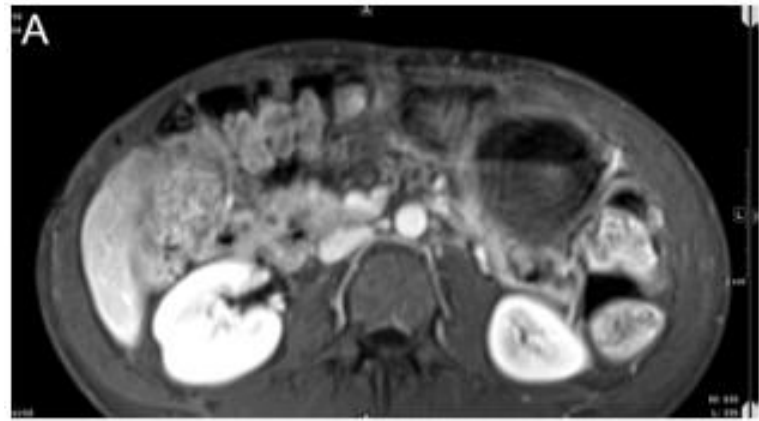

Czink et al. Z Gastroenterol 2016 


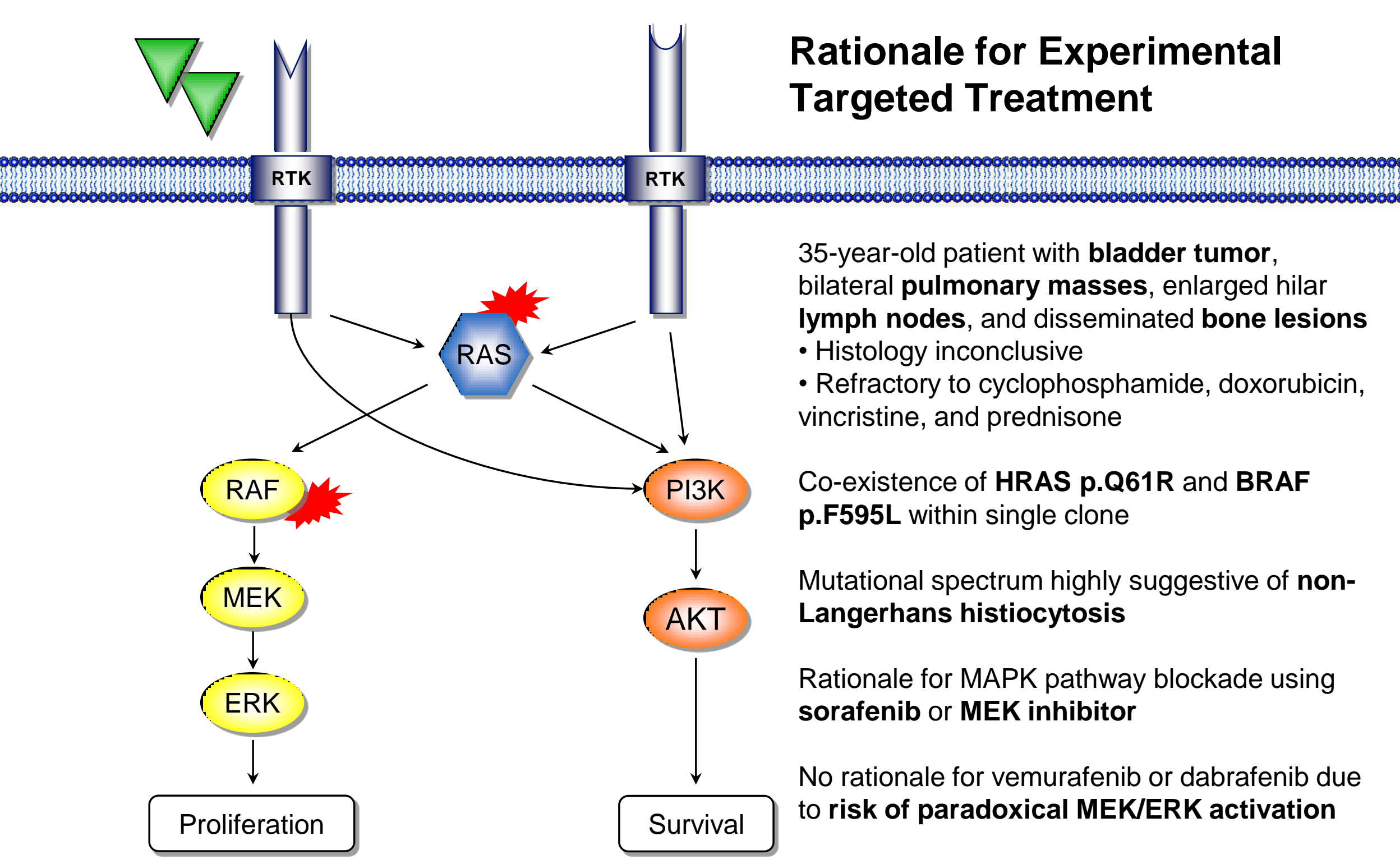

Kordes et al. Leukemia 2016 


\section{NCT MASTER - Case Report II)}

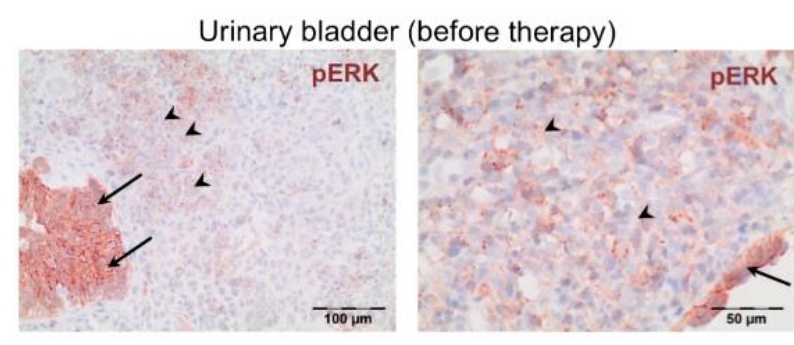

Enteric wall (during sorafenib/interferon therapy)

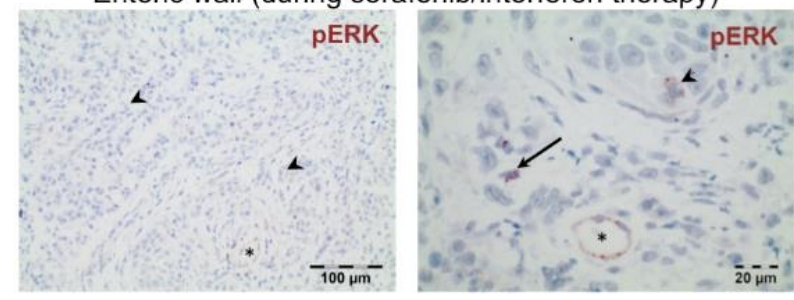

Loss of phosphorylated ERK expression in tumor cells after 3 weeks of sorafenib and interferon alpha treatment

Frequent coexistence of intermediate-activity BRAF mutations and oncogenic RAS in various cancers Wan et al. Cell 2004 COSMIC database

\section{Rationale for Experimental Targeted Treatment}

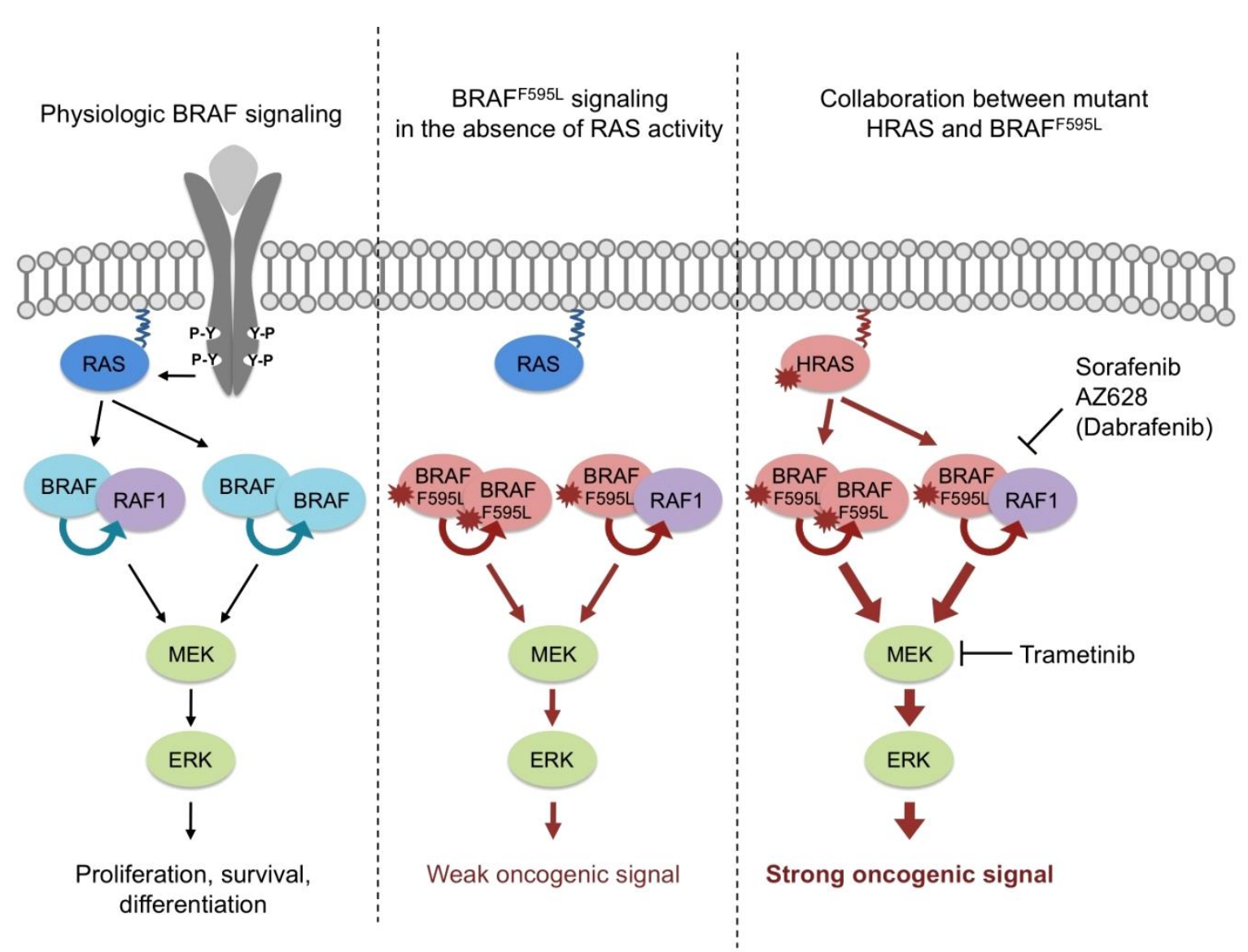

Cooperative activity of BRAF p.F595L and HRAS p.Q61R in aggressive histiocytic sarcoma 


\section{DKTK MASTER \\ Critical Next Steps}

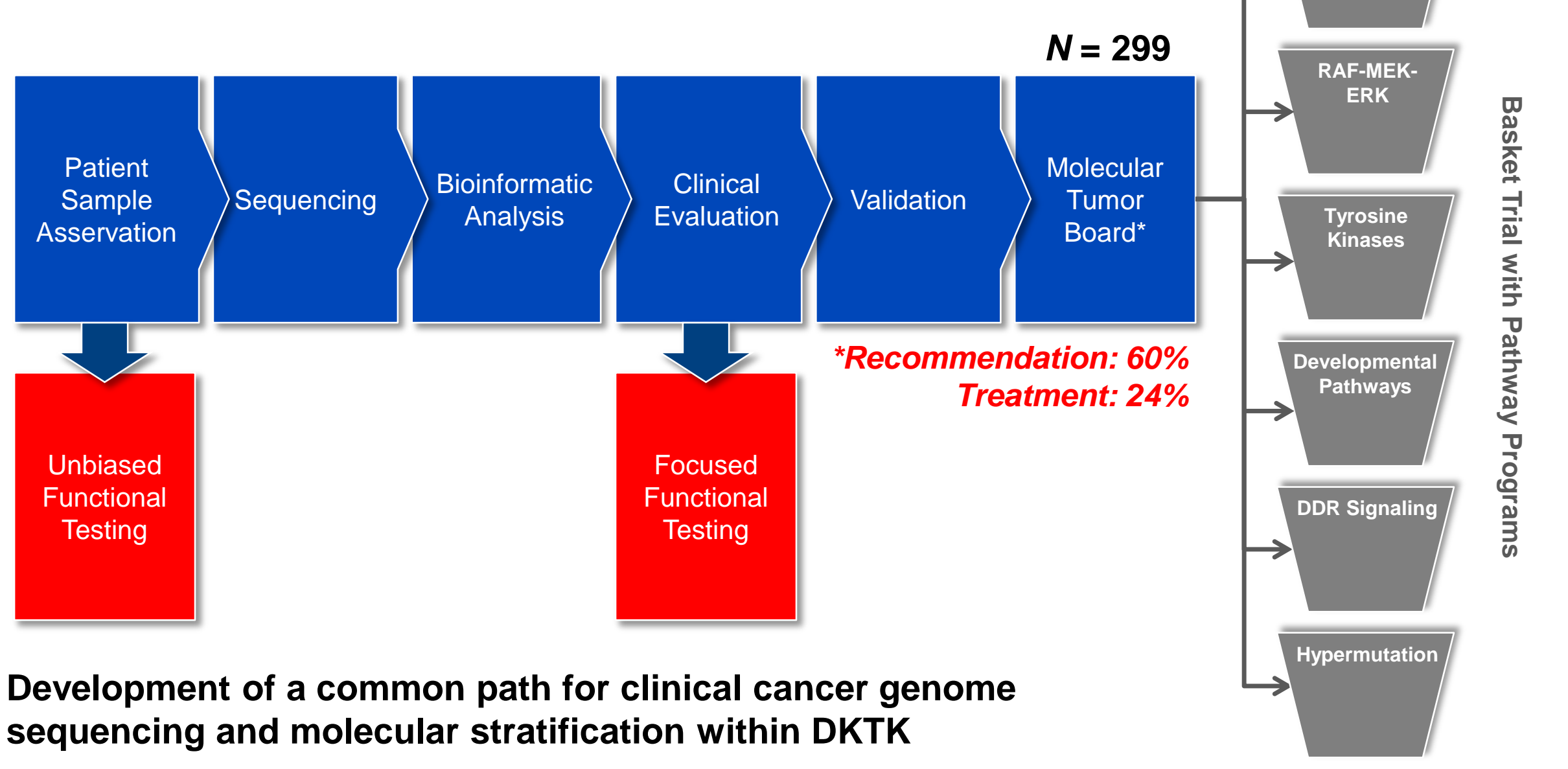

Further development of strategies for clinical translation Refinement and expansion of strategies for functional annotation 


\section{Strategies for Clinical Translation}

\section{Continuous Reassessment with Flexible Extension - CRAFT}

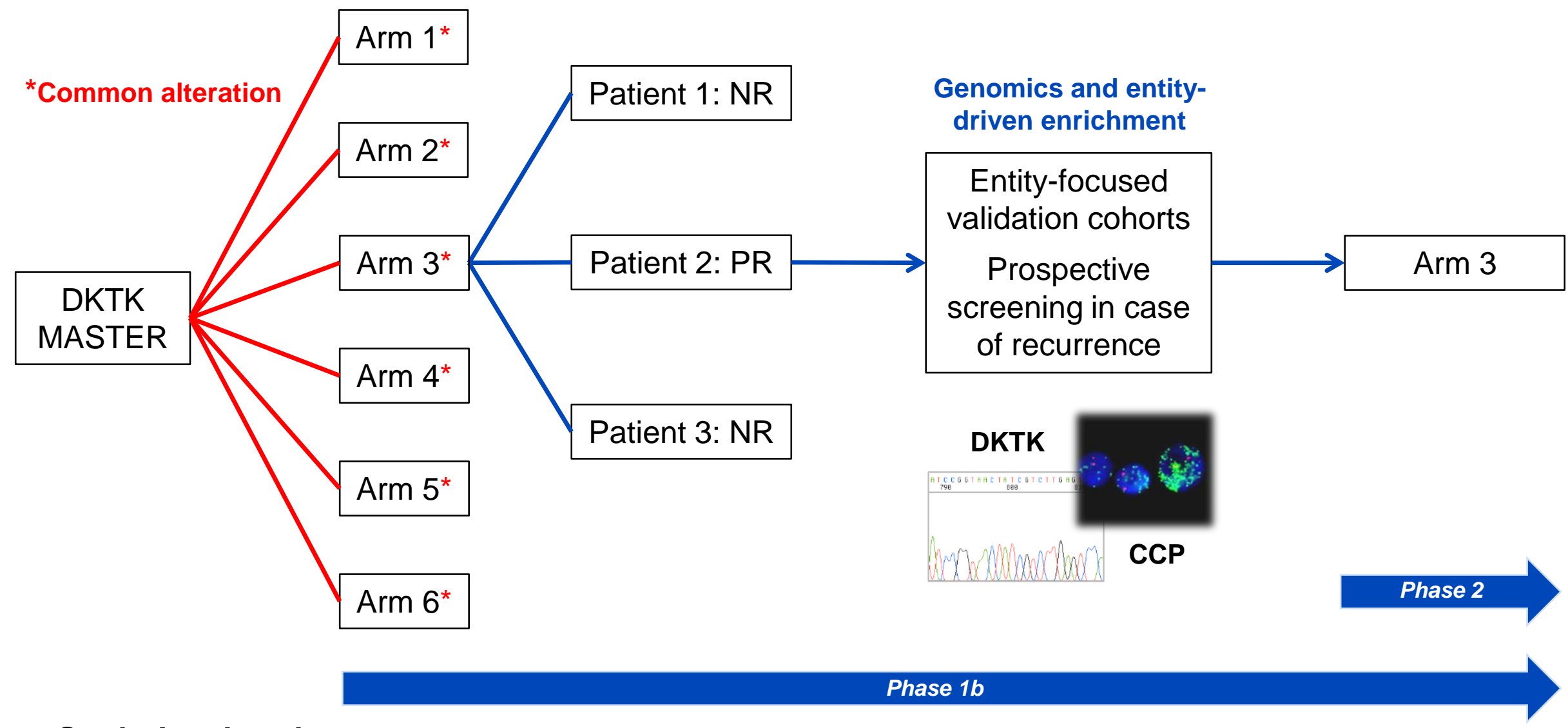

Study Arm Level

Responsible investigators, statistical planning/assessment, molecular pathology, prospective enrichment strategy, phase 1b/2a switch

Richard Schlenk (UIm) Meinhard Kieser (Heidelberg) 


\section{INFORM = INdividualized therapy FOr Relapsed Malignancies in childhood}
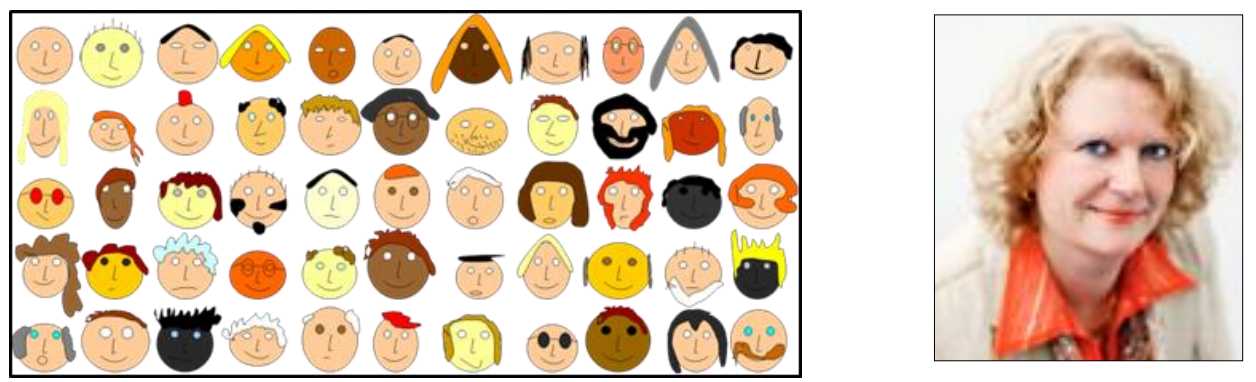

Angelika Eggert

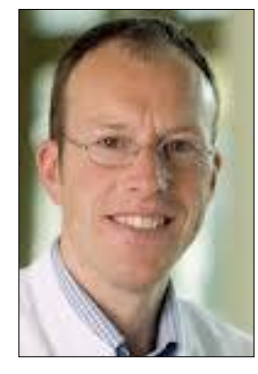

Olaf Witt

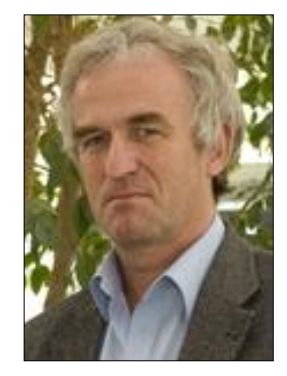

Peter Lichter

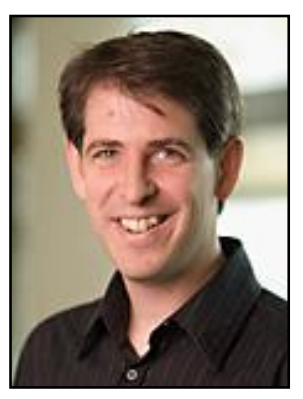

Stefan Pfister

\begin{tabular}{|c|c|}
\hline & $\begin{array}{c}\text { Feasibility-Registry Study } \\
(\text { Year 1+2) }\end{array}$ \\
\hline ALL & AML \\
\hline HGG (incl. DIPG) & Medullo/Ependym. \\
\hline Ewing Sarcoma & Neuroblastoma \\
\hline NHL & Osteosarcoma \\
\hline Rhabdomyosarcoma & Rhabdoid Tumors \\
\hline
\end{tabular}
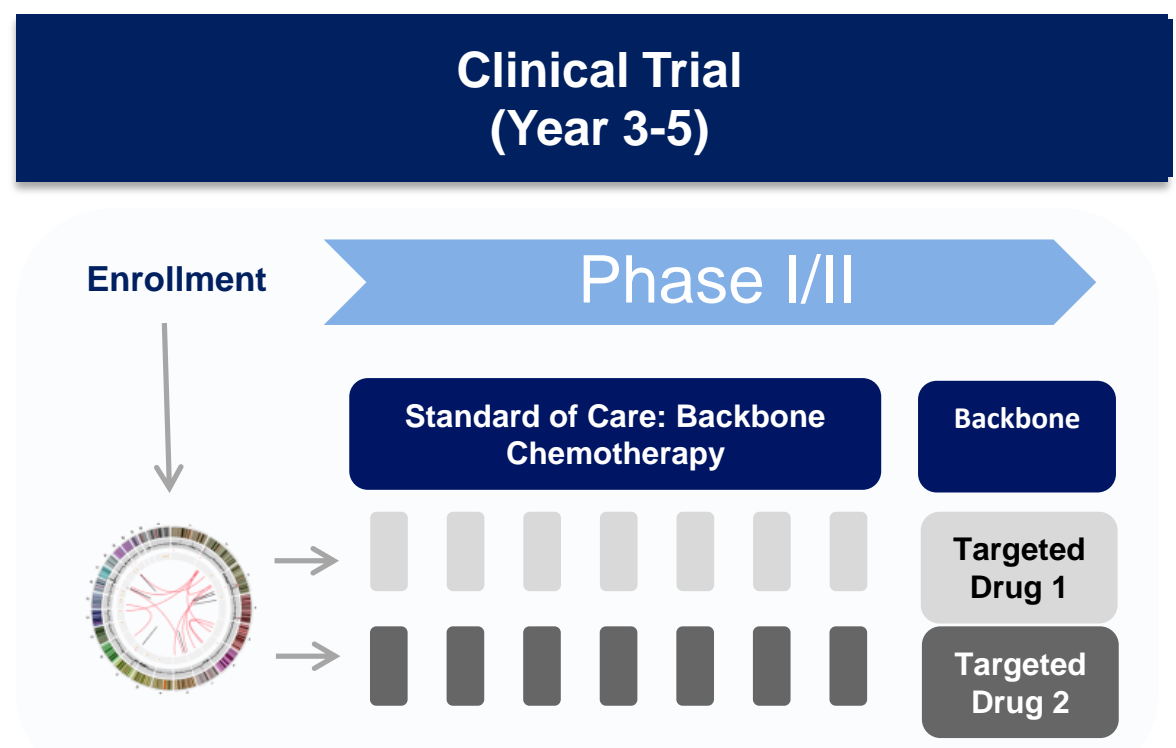


\section{Somatic 'drivers' in medulloblastoma}

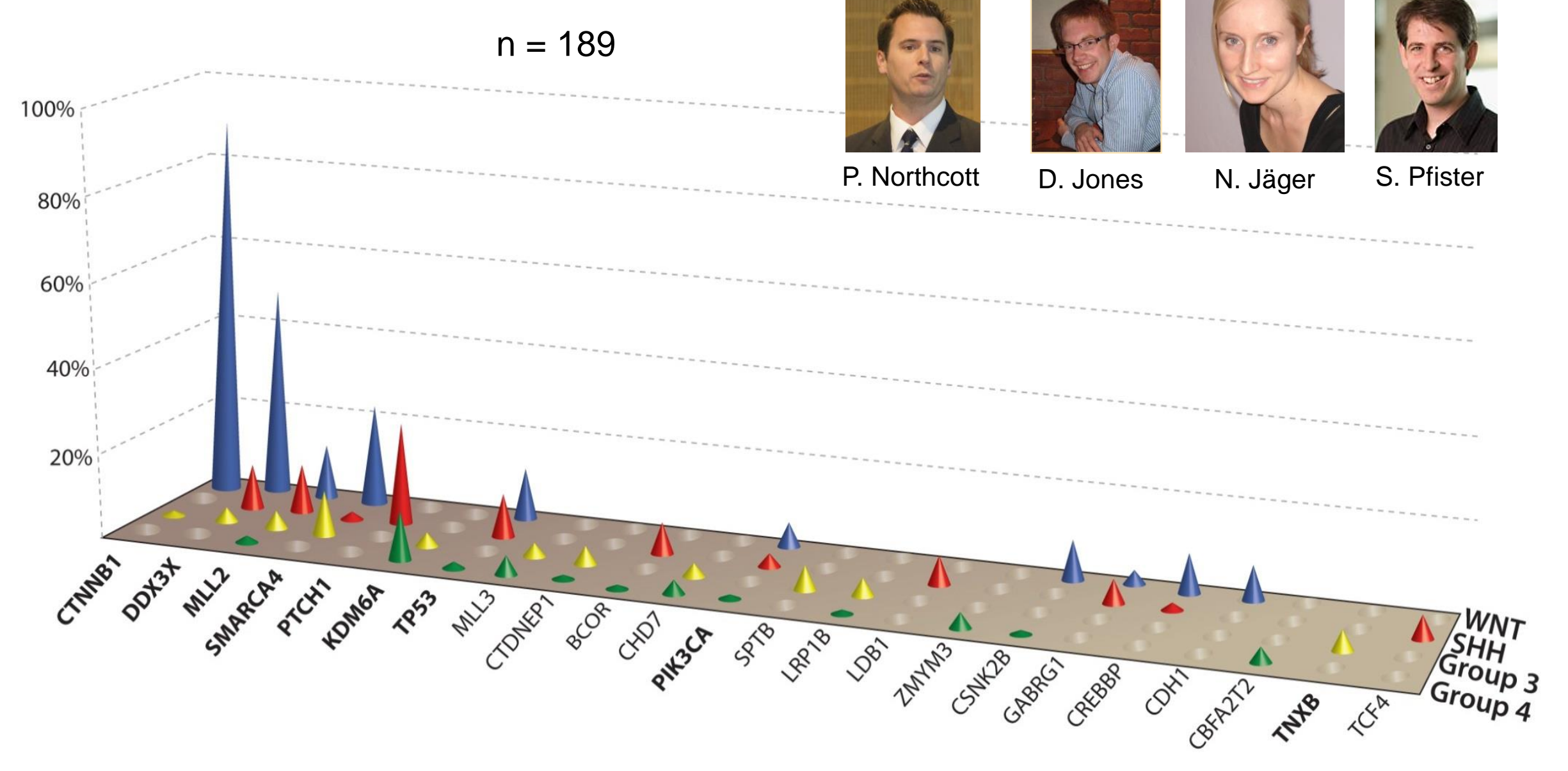

Northcott et al., Nature Reviews Cancer 2012 


\section{What else is out in the genome}

\section{ARTICLE}

doi: $10.1038 /$ nature 13379

\section{Enh}

Onc Hiechl.. Dannumant TEDT Dunmatan pula noor nn. TERT Promoter Mutations in Familial RESEARCH

\section{RESEARCH ARTICLE}

MOBILE DNA IN CANCER

Extensive transduction of nonrepetitive DNA mediated by L1 retrotransposition in cancer genomes cesses in

Jose M. C. Tubio, ${ }^{1}$ Yilong $\mathrm{Li},{ }^{1 *}$ Young Seok Ju, ${ }^{1 *}$ Inigo Martincorena, ${ }^{1}$ Susanna L. Cooke, ${ }_{-}^{1}$ 


\section{High abundance of fusion genes in breast cancer $\mathrm{O}$ NCT}
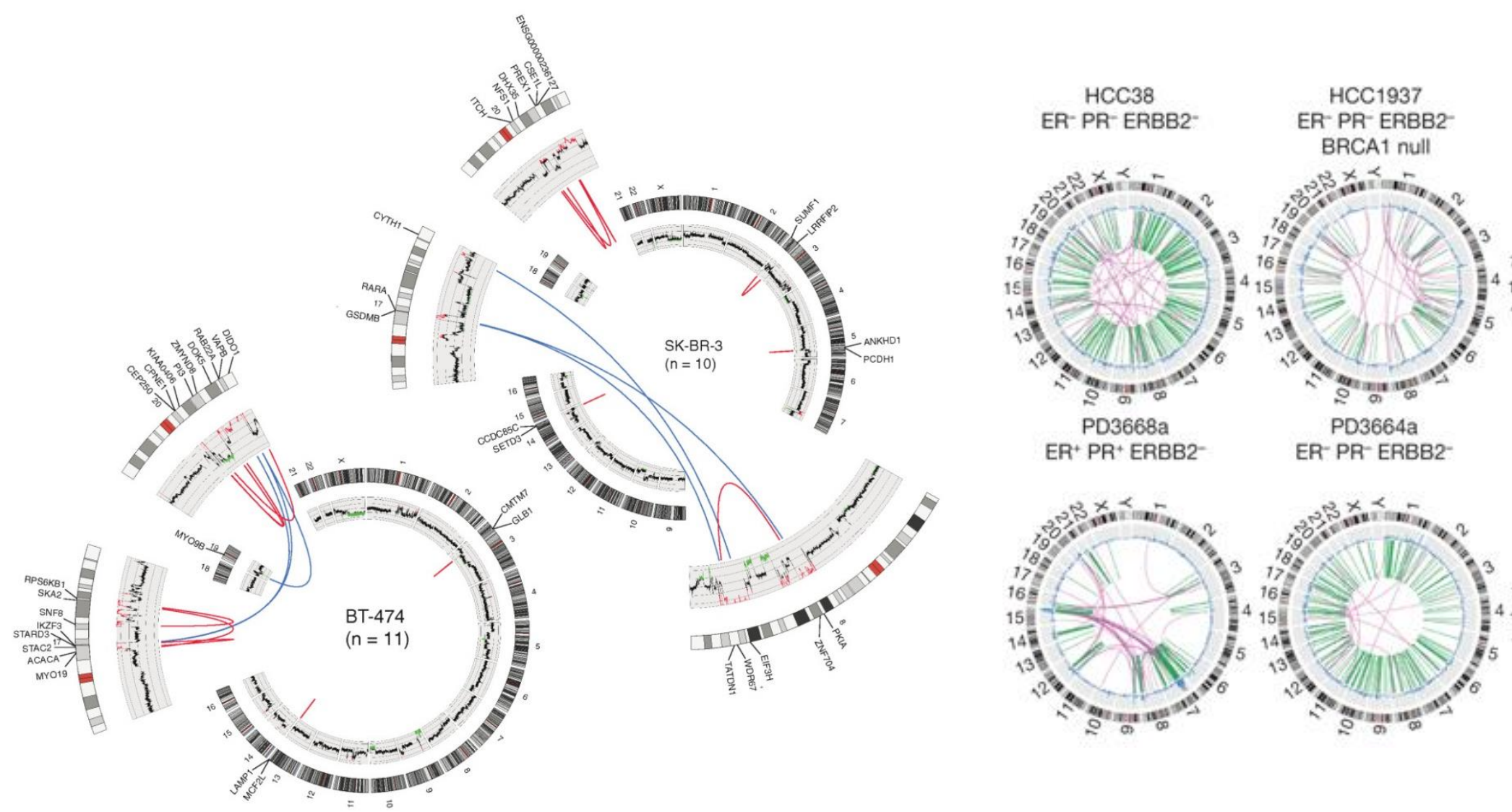

$\mathrm{HCC} 2218$
$-\mathrm{H}^{-}$

ER- PR- ERBB2+
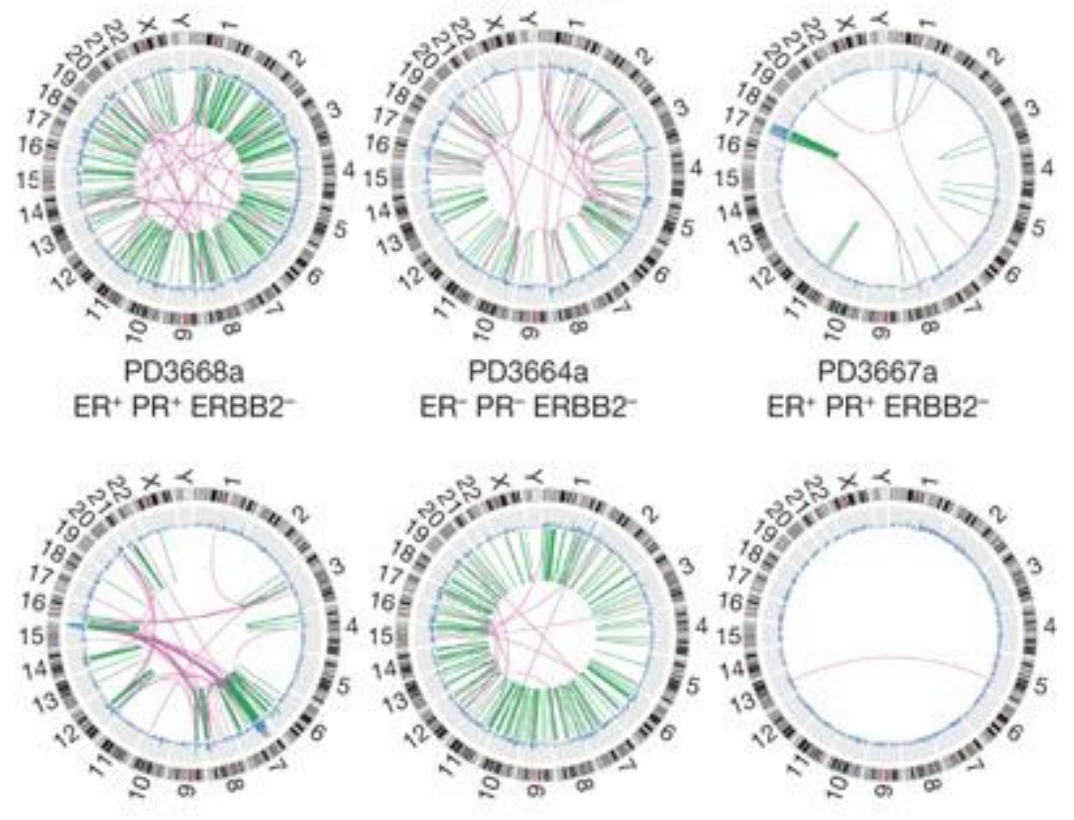

Edgren et al., Genome Biology 2011

Stephens et al., Nature 2009 


\section{A Single Oncogenic Enhancer Rearrangement Causes}

\section{Concomitant EVI1 and GATA2 Deregulation in Leukemia}

Stefan Gröschel ${ }^{1,2,8}$, Mathijs A. Sanders ${ }^{1,8}$, Remco Hoogenboezem ${ }^{1}$, Elzo de Wit ${ }^{3}$, Britta A.M. Bouwman ${ }^{3}$, Claudia Erpelinck', Vincent H.J. van der Velden ${ }^{4}$, Marije Havermans ${ }^{1}$, Roberto Avellino ${ }^{1}$, Kirsten van Lom', Elwin J. Rombouts ${ }^{1}$, Mark van Duin', Konstanze Döhner ${ }^{2}$, H. Berna Beverloo ${ }^{5,6}$, James E. Bradner ${ }^{7,8}$, Hartmut Döhner ${ }^{2}$, Bob Löwenberg', Peter J.M. Valk', Eric M.J. Bindels ${ }^{1}$, Wouter de Laat ${ }^{3}$, Ruud Delwel'

Dual gene deregulation in inv(3) AML
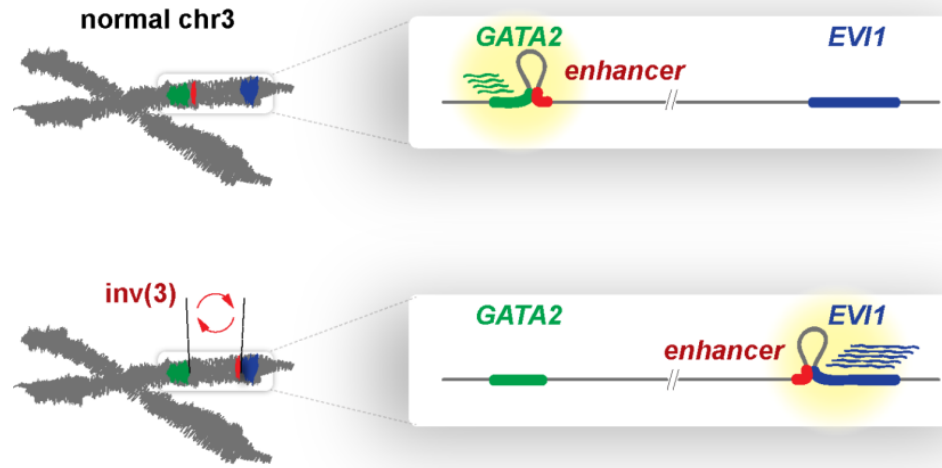

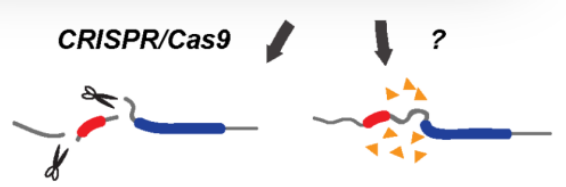

Monocyte/macrophage differentiation upon enhancer deletion
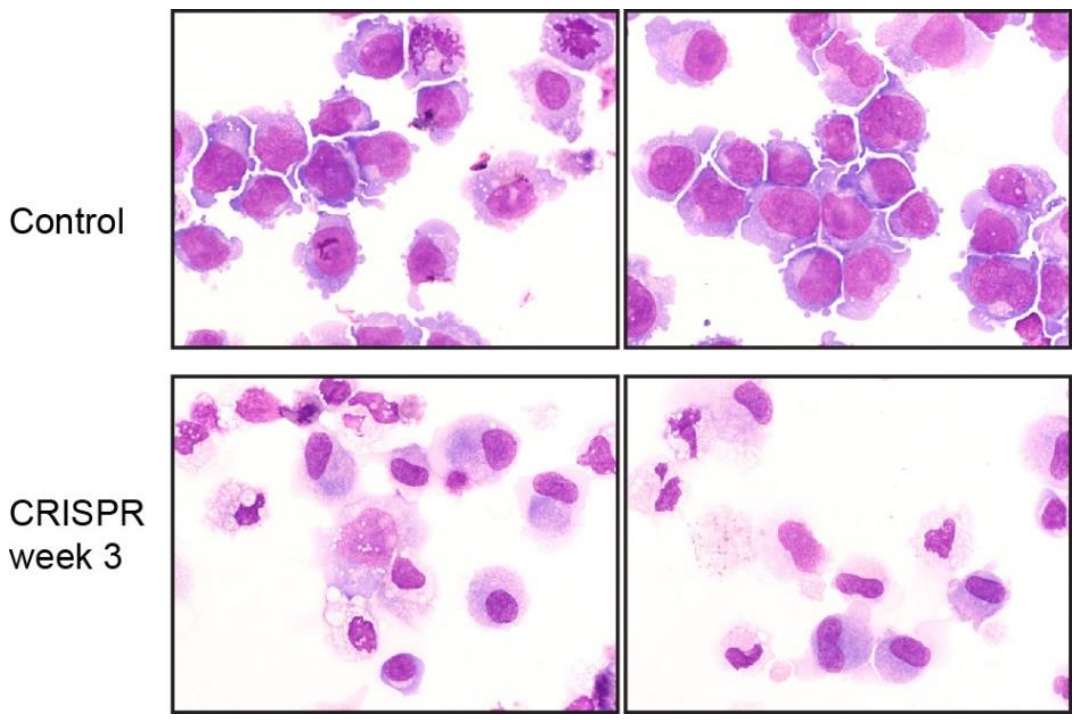


\section{Examples of other NonCodingMutations:}

- Mansour et al., 2014, Science 346, 1373: An oncogenic super-enhancer formed through somatic mutation of a noncoding intergenic element. (R. Young)

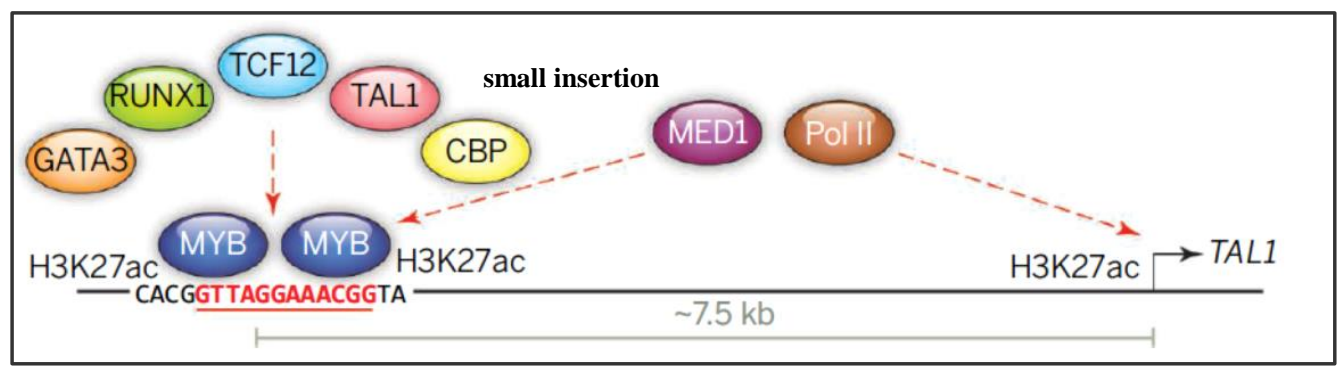

(T-ALL)

- Weinhold et al., 2014, Nat. Genetics 46, 1160: Genome-wide analysis of noncoding regulatory mutations in cancer. (PLEKHS1, WDR74) (C. Sander)

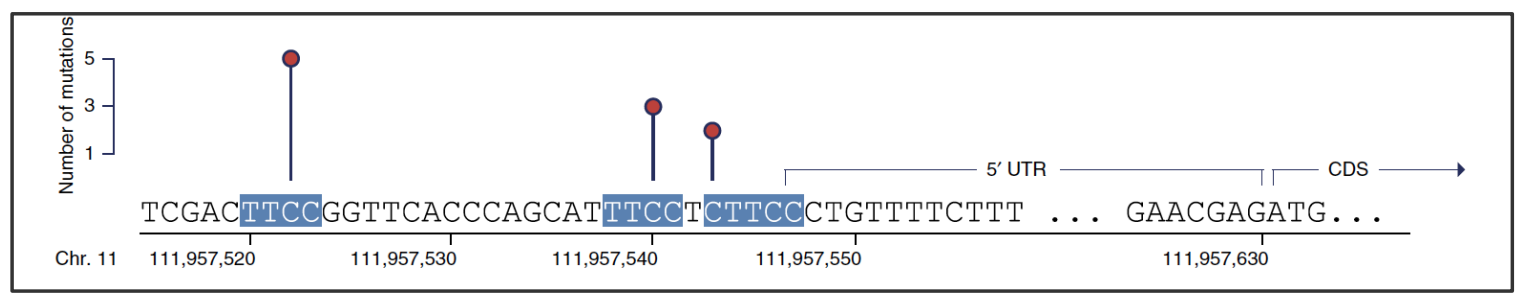

(Bladder Ca.)

- Denisova et al., 2015, Oncotarget 6, 35922: Frequent DPH3 promoter mutations in skin cancers ( $R$. Kumar) (skin cancer: SCC, BCC)

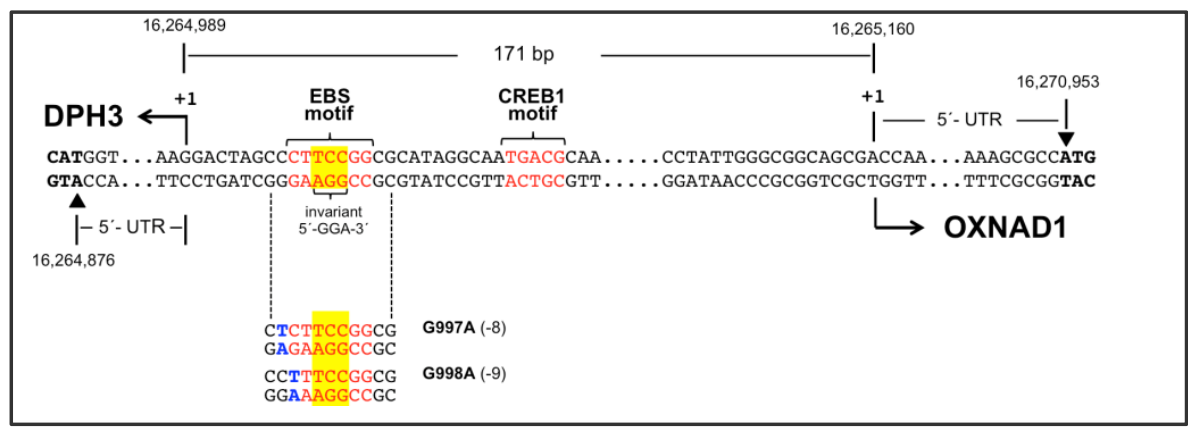




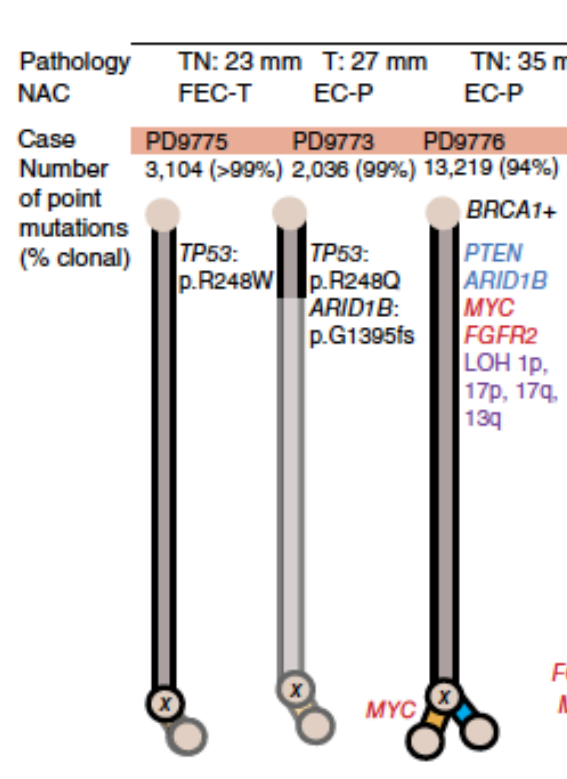

TN cancers: neo-adjuvant chemotherapy

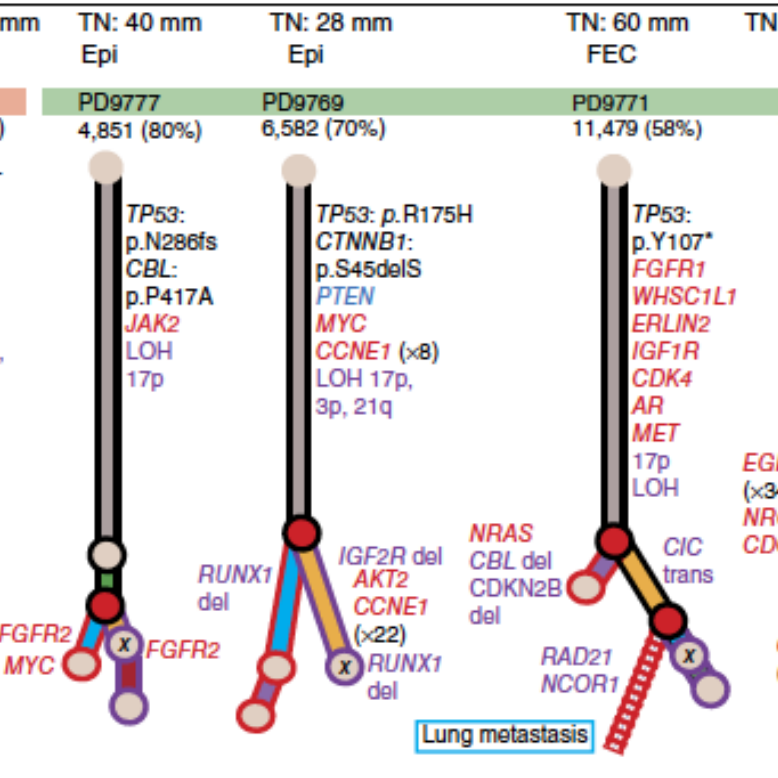

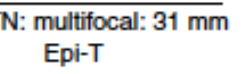

PD9770

7,624 (40\%)

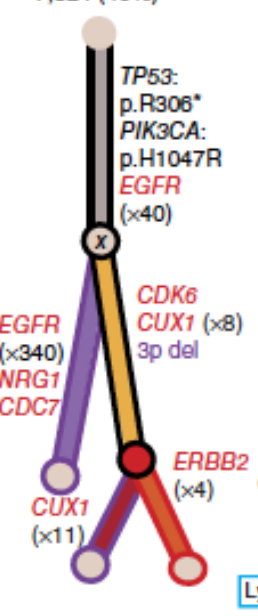

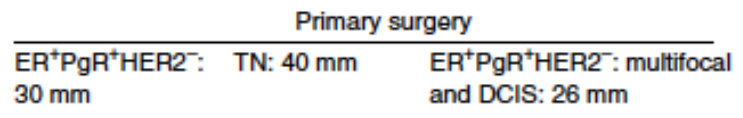

PD.949

\begin{tabular}{lll} 
PD9849 & PD9852 & PD9694 \\
\hline $4,212(91 \%)$ & $6,231(83 \%)$ & $3,371(16 \%)$
\end{tabular}

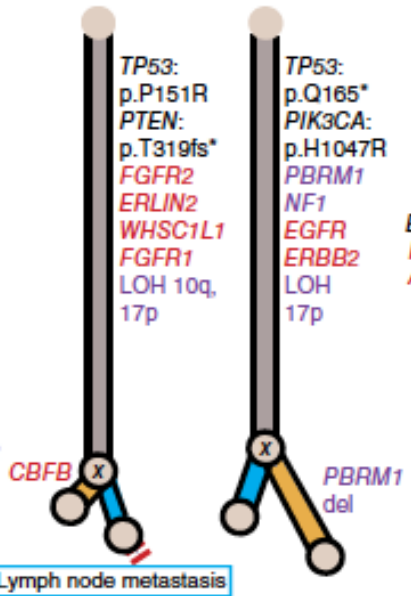

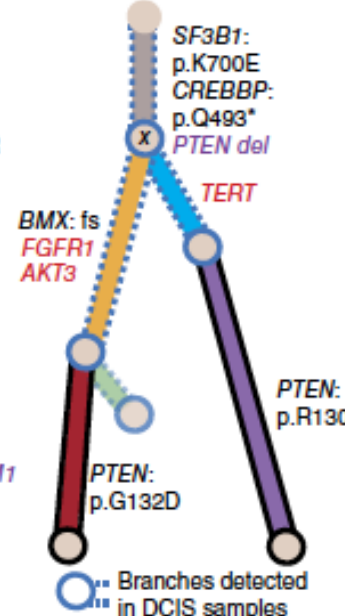

- highly variable subclonal diversification

- no strict temporal order

- alterations in driver genes occurring early in some tumors and late in others

- resistance to therapy and invasive potential arose from subclones that were detectable in early lesions

$=>$ Necessity to include subclonal and longitudinal analysis in clinical trials of primary breast cancer 


\section{LIQUID BIOPSIES}

Analysis of body fluids: Blood, Plasma, Sputum, Urine, Spinal Fluid

Focus on circulating tumor cells (CTCs) and circulating tumor DNA (ctDNA), for

- Prognosis

- Prediction

- Molecular Heterogeneity

- Identification of drug targets

- Monitoring of therapy response

- Monitoring of resistence mechanisms

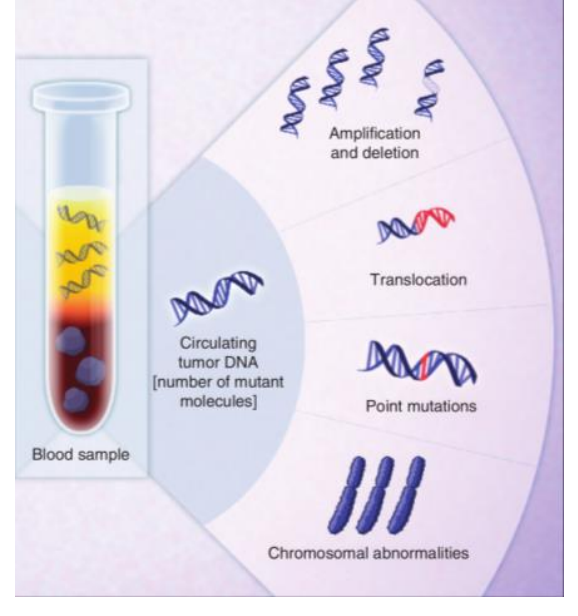

Haber et al. Cancer Discov 2014

"non"-invasive approach to generate genetic tumor profiles 


\section{Functional Genomics}

\section{Development of experimental systems for functional validation}

Stefan Fröhling, Claudia Scholl, Michael Boutros (NCT Heidelberg/DKFZ) and Frank Buchholz (NCT Dresden)

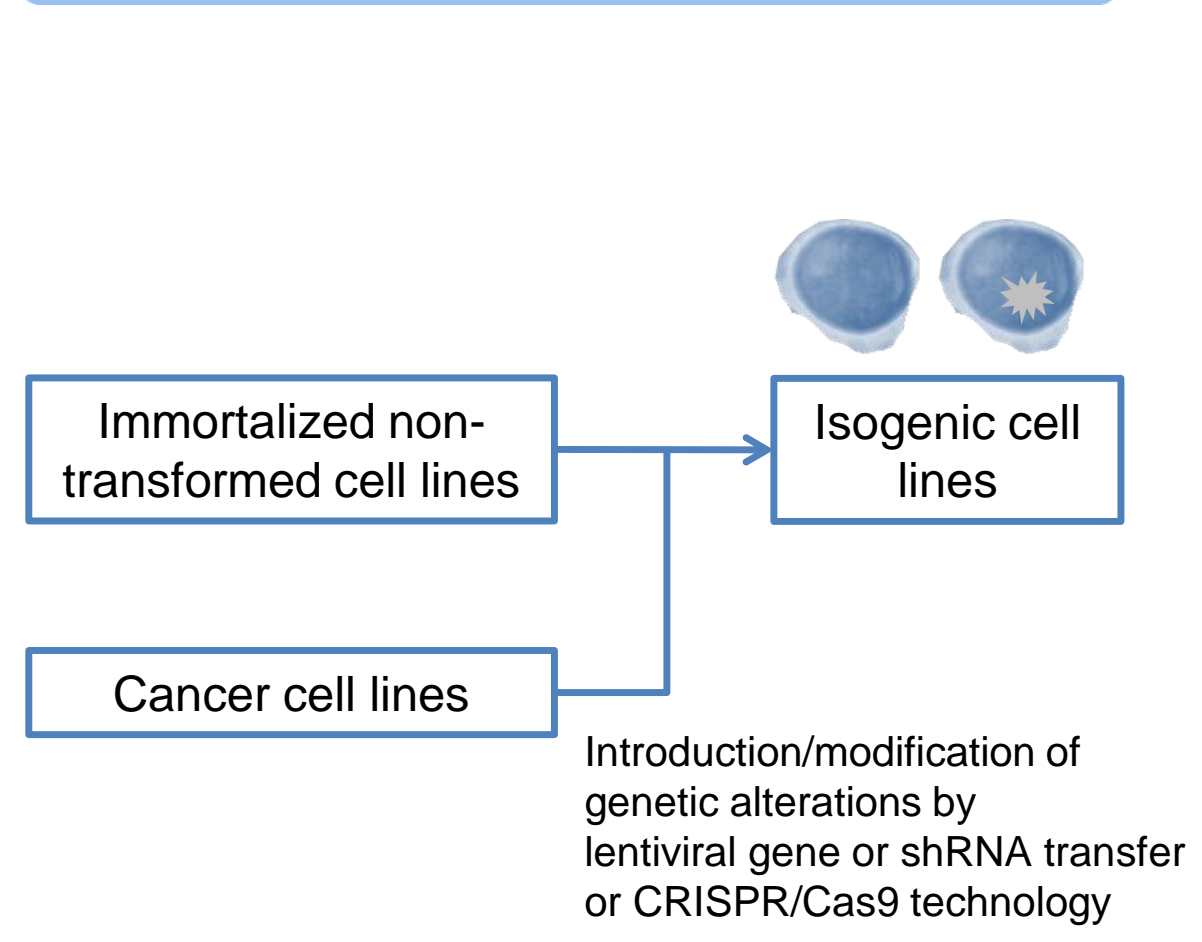

\section{Functional annotation of} molecular lesions
- Viability/proliferation

- Apoptosis/cell cycle

- Anchorage independence

- Invasion/migration

- Pathway activation

- Others

- Tumorigenicity (mouse, CAM)

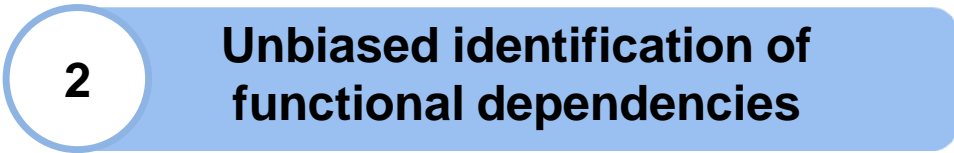

- Genome-wide or targeted shRNA screens

- Genome-wide or targeted CRISPR/Cas9 screens 


\section{NCT DataThereHouse}

\section{Current Scenario}

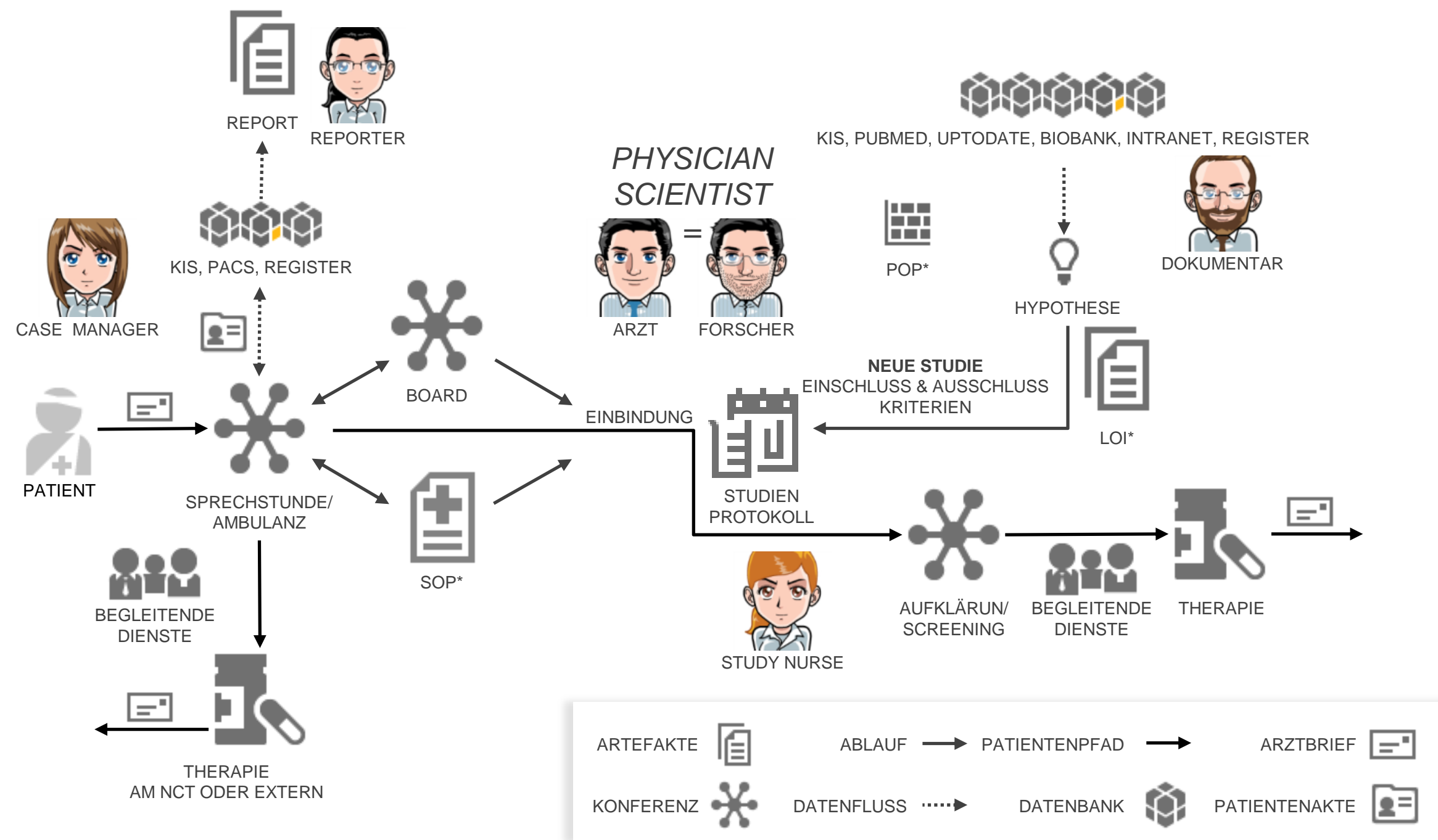




\section{NCT DataThereHouse}

\section{NCT Clinical Development Strategy}

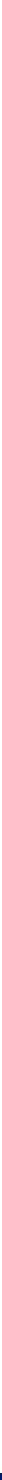




\section{Translational Oncology...}

\section{ONCT}

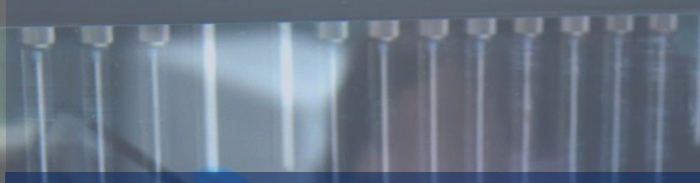
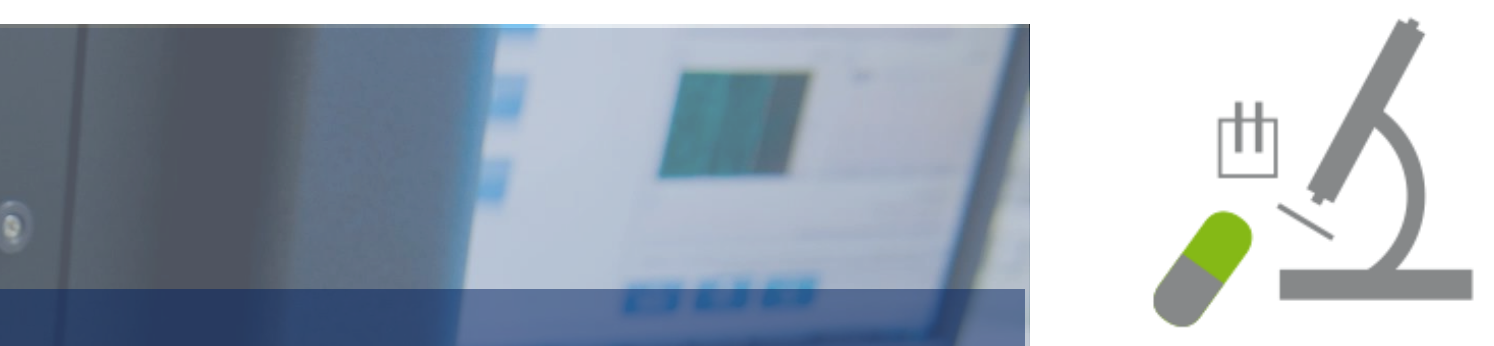

- needs to RETHINK the old \& the new

- needs SMART Data

- is a TEAM Effort
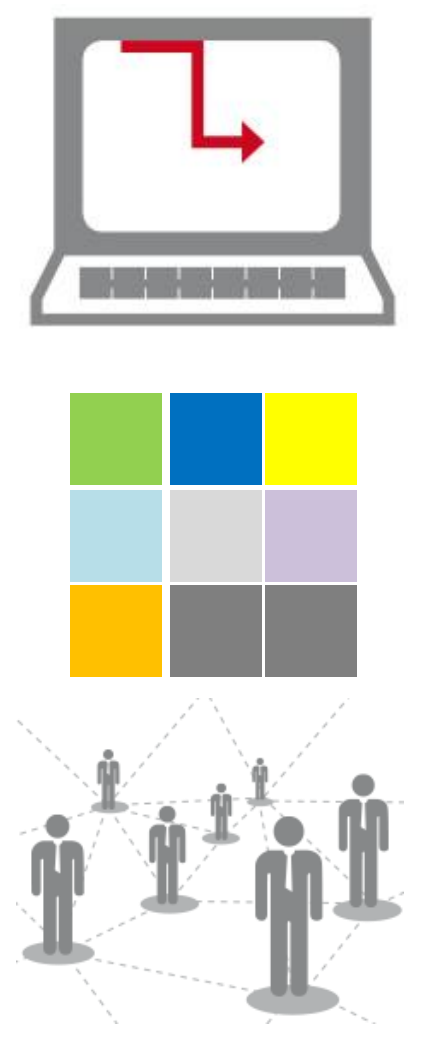


\section{NCT Partnerships}

\section{Academic Collaboration}
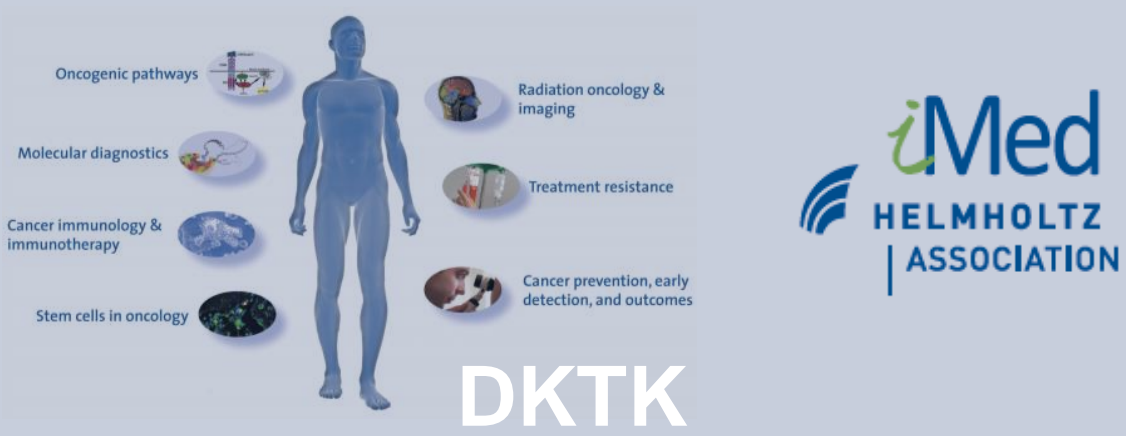

Joint Industry-Academia Collaboration

\section{Roche}
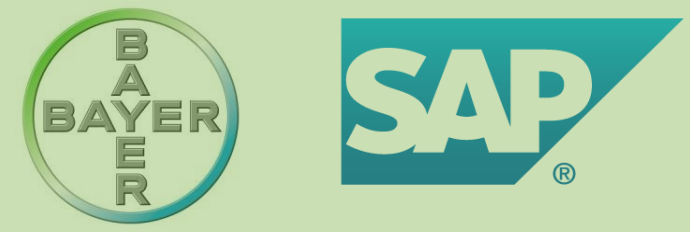

Cancer Core Europe Consortium Centers

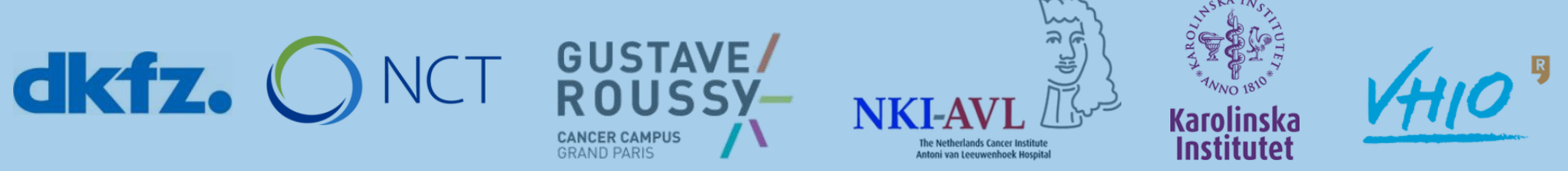


NATIONAL CENTER FOR TUMOR DISEASES

\section{NCT HEIDELBERG}

THANK YOU

dkfz.

NCT
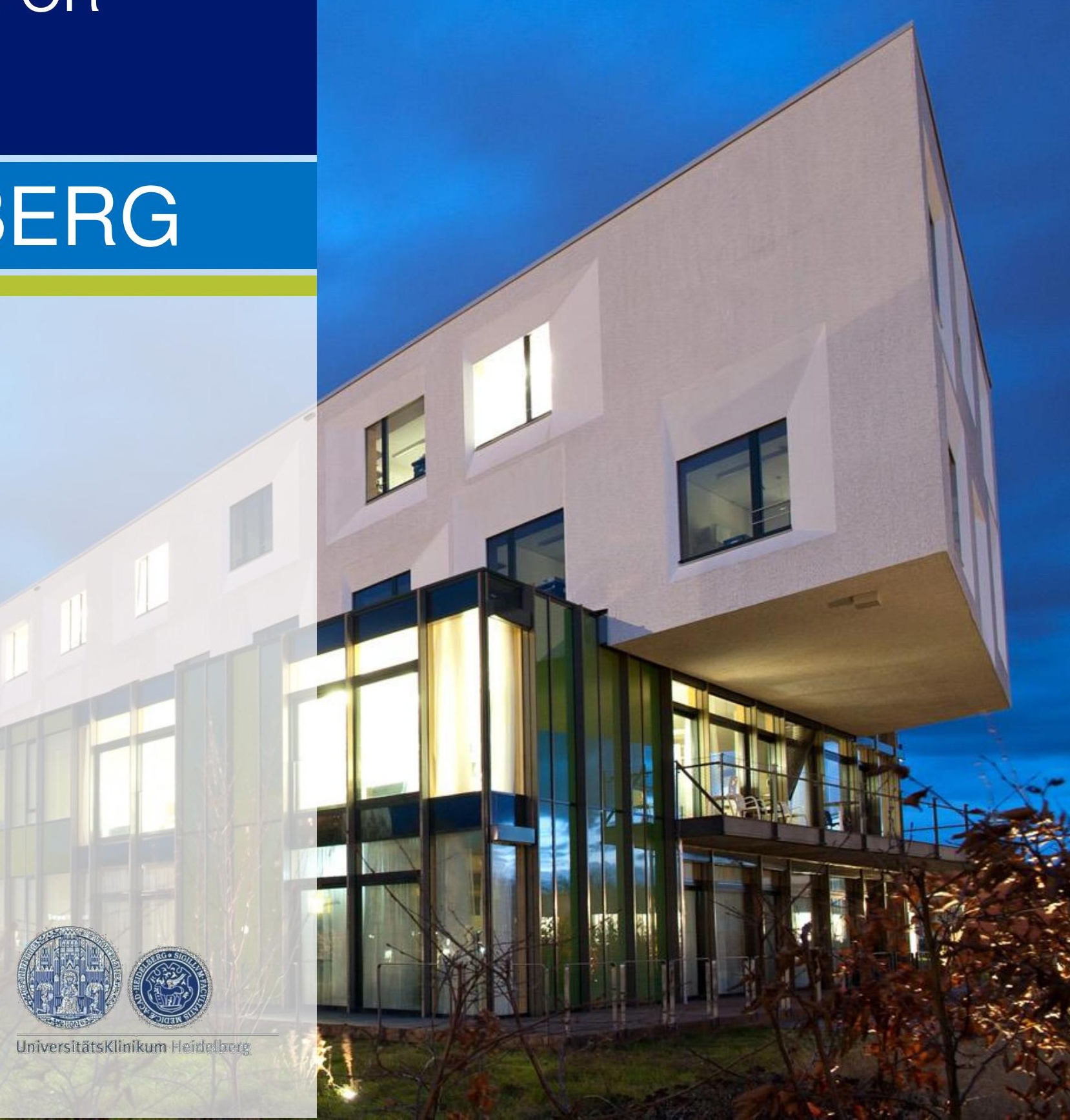